Estudio IESE-Penteo sobre transformación + digital

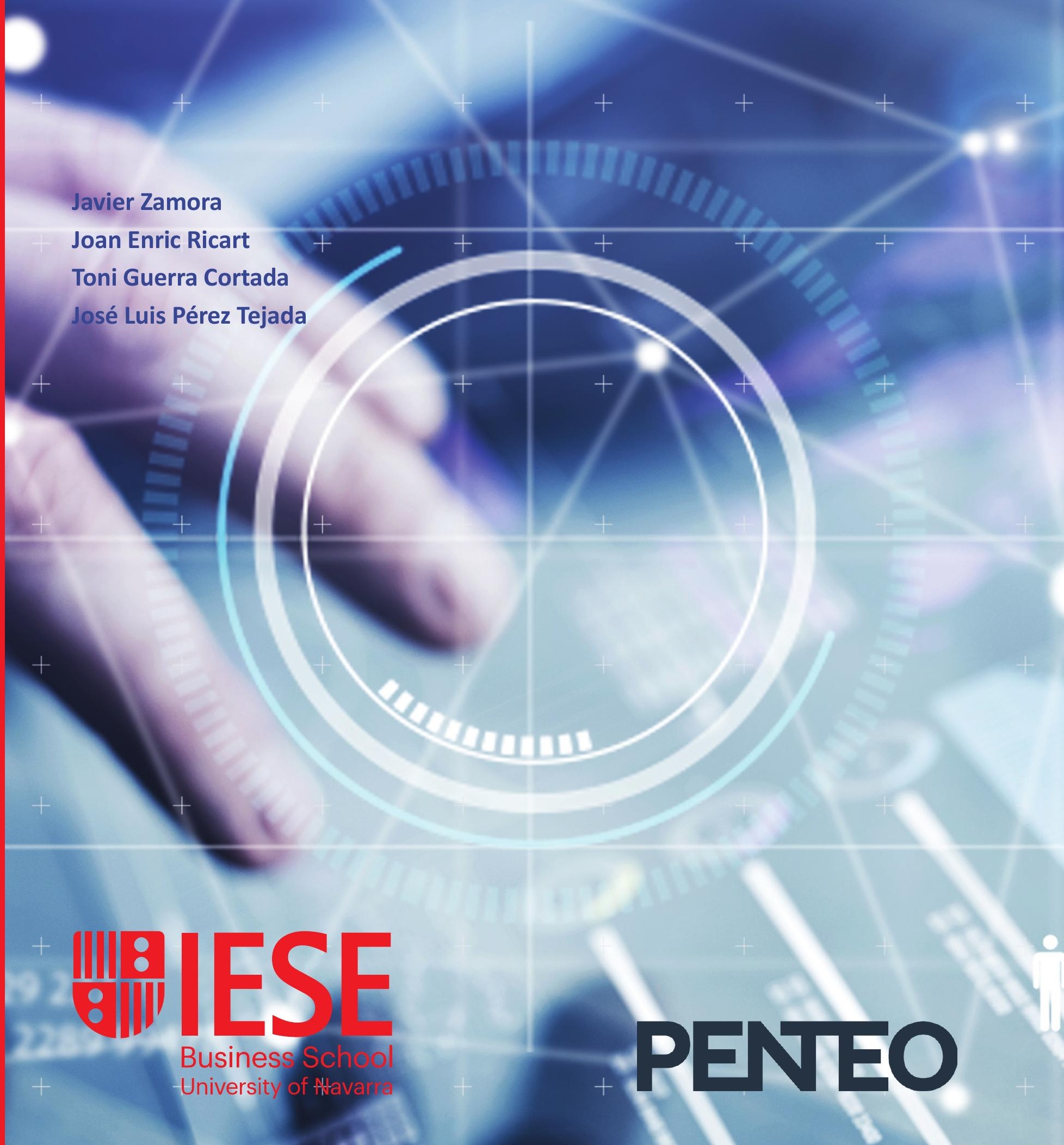




\section{Estudio IESE-Penteo sobre transformación digital}

Javier Zamora

Joan Enric Ricart

Toni Guerra Cortada

José Luis Pérez Tejada 

INTRODUCCIÓN

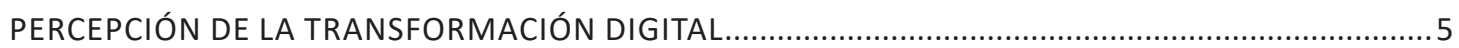

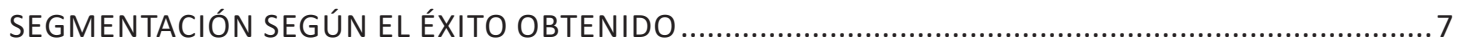

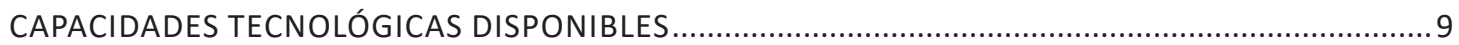

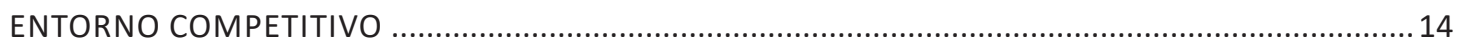

LIDERAZGO Y ORGANIZACIÓN DE LA TRANSFORMACIÓN DIGITAL..............................................17

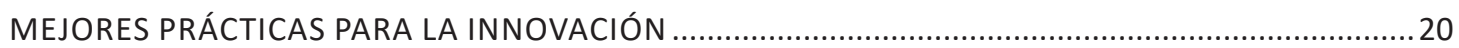

CONCLUSIONES

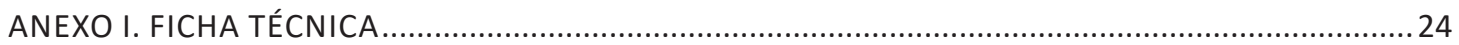

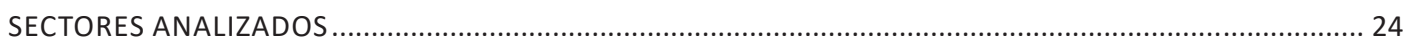

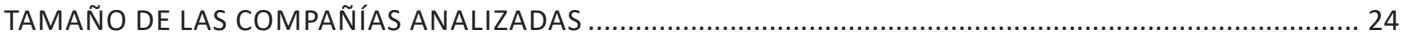

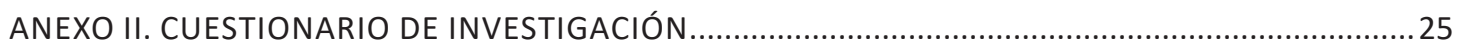

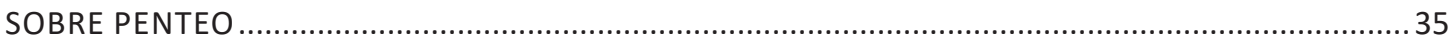

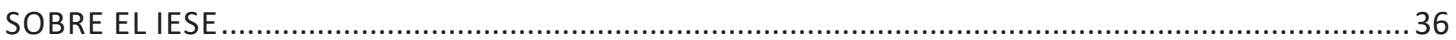

Todo el material incluido en este documento ha sido elaborado por los autores a partir de la encuesta 2019 sobre transformación digital de la empresa española llevada a cabo por Penteo \& IESE Business School. 


\section{Introducción}

Desde Penteo, firma de análisis tecnológico con conocimiento del mercado español, y el IESE Business School, hemos querido descifrar las claves de la transformación digital en España, analizando el momento en el que se encuentran las empresas de nuestro país en los procesos de transformación, así como los principales retos y oportunidades que se les presentan en el entorno actual.

Para ello, se ha realizado un estudio conjunto que muestra una radiografía del ecosistema digital español, con el objetivo de responder a la siguiente pregunta:

\section{¿Cuáles son las claves de la adopción tecnológica y de qué forma contribuyen positivamente a la transformación digital de las compañías?}

\section{Contexto}

El análisis se ha llevado a cabo con la participación de 207 directivos, con el fin de obtener la perspectiva de los CEO y sus comités de dirección. Los ámbitos estudiados han girado en torno a la visión digital de los directivos, la valoración del éxito obtenido hasta la fecha, la adopción de capacidades tecnológicas y el impacto en modelo de negocio y liderazgo.

La metodología ha incluido tanto cuestionarios online como entrevistas cualitativas, realizados durante el tercer y el cuarto trimestre del 2019. Así pues, el efecto de la COVID-19 no queda recogido en las respuestas y, con total seguridad, algunos de los resultados habrían sido diferentes.

El 9 de octubre del 2019, Penteo y el IESE expusieron una presentación preliminar de los resultados del estudio durante la jornada del Programa Digital Ecosystem: Bringing value through Al, celebrado en el campus de IESE en Madrid. 


\section{Percepción de la transformación digital}

El concepto "transformación digital" tiene múltiples significados, en función de la organización, el área directiva y el sector en el cual opere la empresa. A partir de los factores básicos que creemos abarcan los procesos de transformación digital, hemos preguntado a los directivos qué peso tienen dichos factores en su concepción de la misma. Estas han sido las respuestas y su valoración:

\section{Figura 1. Visión digital}

Pregunta: Indique qué factores considera que definen el concepto de "transformación digital". Valorada de 1 "Poco" a 3 "Completamente".

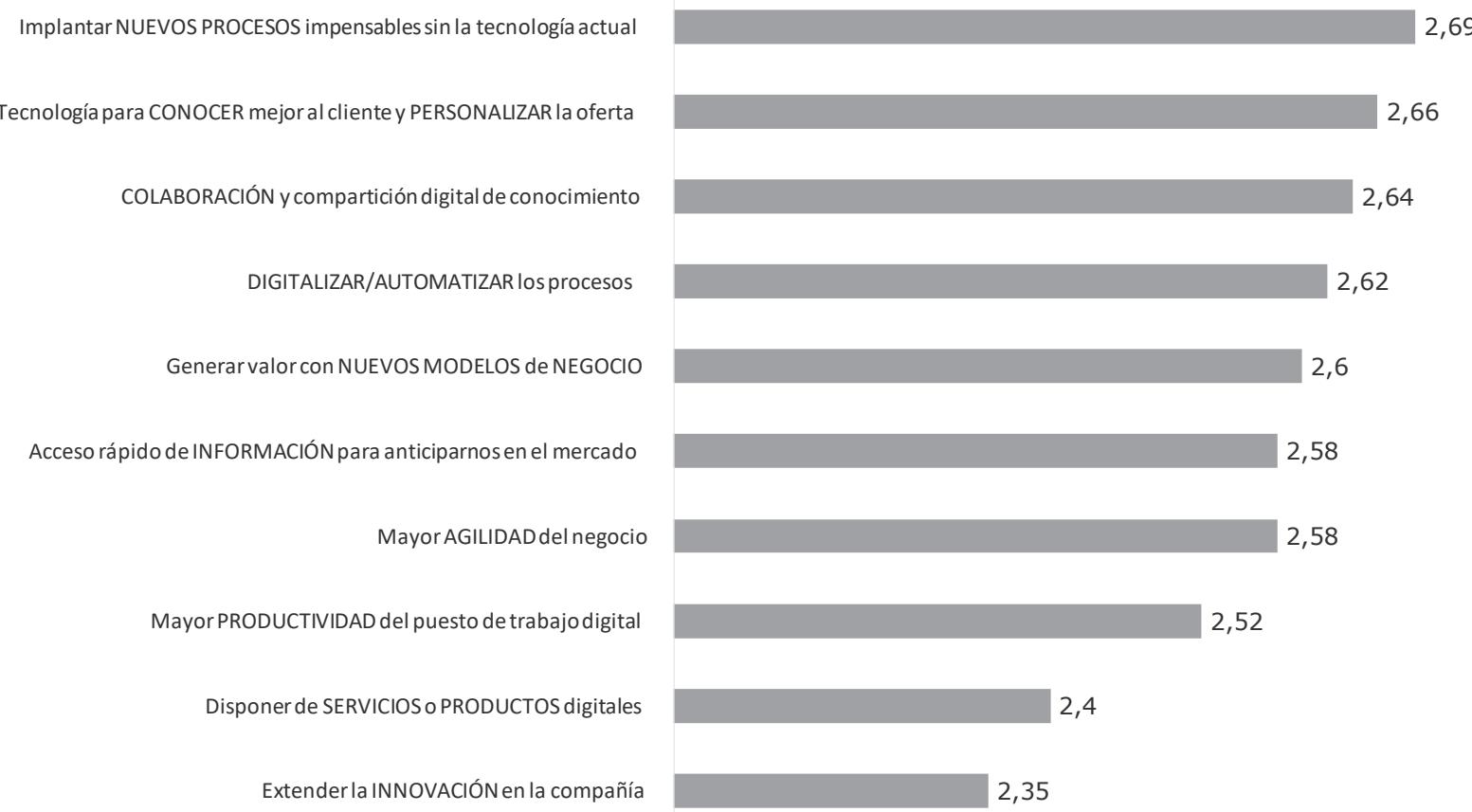

La transformación digital es un "plato" complejo, de texturas muy diversas y que incluye todos los ingredientes propuestos con una proporción bastante parecida entre ellos. A primera vista, solo hay dos aspectos de los propuestos que destacan respecto al resto con una menor valoración: extender la innovación en la compañía y ofrecer servicios o productos digitales.

Sin embargo, si nos centramos únicamente en las respuestas del grupo de empresas que indican que su grado de éxito (es decir, "con éxito") en sus iniciativas de transformación digital está por encima de sus expectativas (13\% de las compañías, según se explica la siguiente sección), hay matices muy significativos. 


\section{Figura 2. Visión digital de las empresas "con éxito"}

Respuestas, en porcentaje, a la pregunta "Indique qué factores considera que definen el concepto de 'transformación digital". Diferencia en puntuación (desde 1 "Poco" a 3 "Completamente"), del segmento de empresas con éxito respecto a la puntuación del total de empresas.

Generar valor con NUEVOS MODELOS de NEGOCIO

Acceso rápido de INFORMACIÓN para anticiparnos en el mercado

Tecnología para CONOCER mejor al cliente y PERSONALIZAR la oferta

Disponer de SERVICIOS o PRODUCTOS digitales

Mayor AGILIDAD del negocio

Mayor PRODUCTIVIDAD del puesto de trabajo digital

COLABORACIÓN y compartición digital de conocimiento

Implantar NUEVOS PROCESOS impensables sin la tecnología actual

Extender la INNOVACIÓN en la compañía

DIGITALIZAR/AUTOMATIZAR los procesos

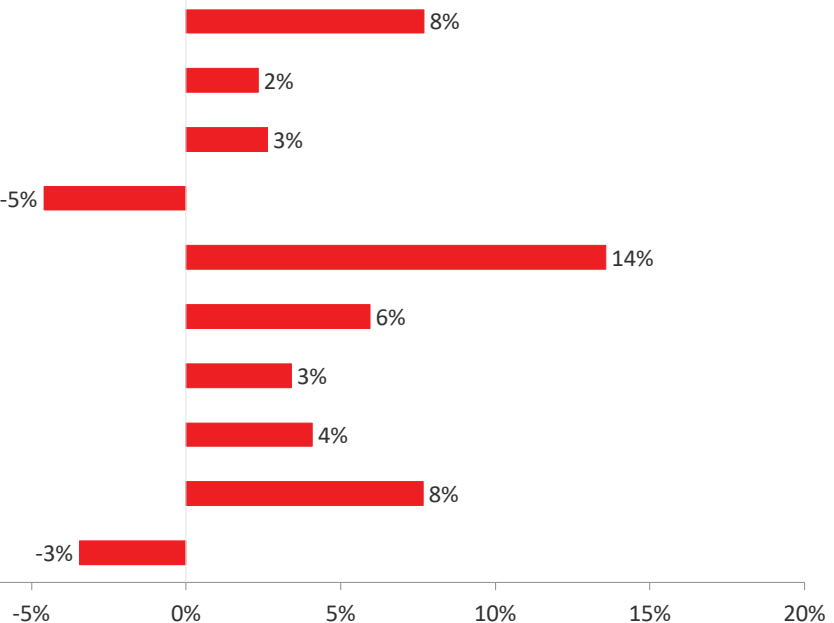

Si bien todos los aspectos resultan necesarios, hay cuatro que son elementos diferenciales para las empresas que han tenido éxito:

1. Mayor agilidad del negocio.

2. Extender la innovación en la compañía.

3. Generar valor con nuevos modelos de negocio.

4. Mayor productividad del puesto de trabajo digital. 


\section{Segmentación según el éxito obtenido}

La mayoría de las empresas que han iniciado una estrategia orientada a la transformación digital ha conseguido tener éxito, según su comité de dirección. En concreto, un 47\% opina que ha cumplido con las expectativas generadas inicialmente y otro $13 \%$ considera que se han superado. En adelante, a lo largo del documento nos referiremos a este último grupo de empresas como "grupo de 'éxito'" (las que superan expectativas).

Quizá estemos ante un exceso de complacencia por parte de los directivos (al saberse responsables de esa estrategia), puesto que solo el $1 \%$ admite haber fracasado.

\section{Figura 3. Éxito obtenido en transformación digital}

Pregunta: En caso de haber iniciado durante los últimos años alguna estrategia de transformación digital, valore el éxito. Valorada de 1 "Se ha fracasado" a 4 "Mejora de expectativas iniciales". Las gráficas del grupo de "éxito" quedarán diferenciadas en tonalidad naranja, según el patrón mostrado en esta misma gráfica.

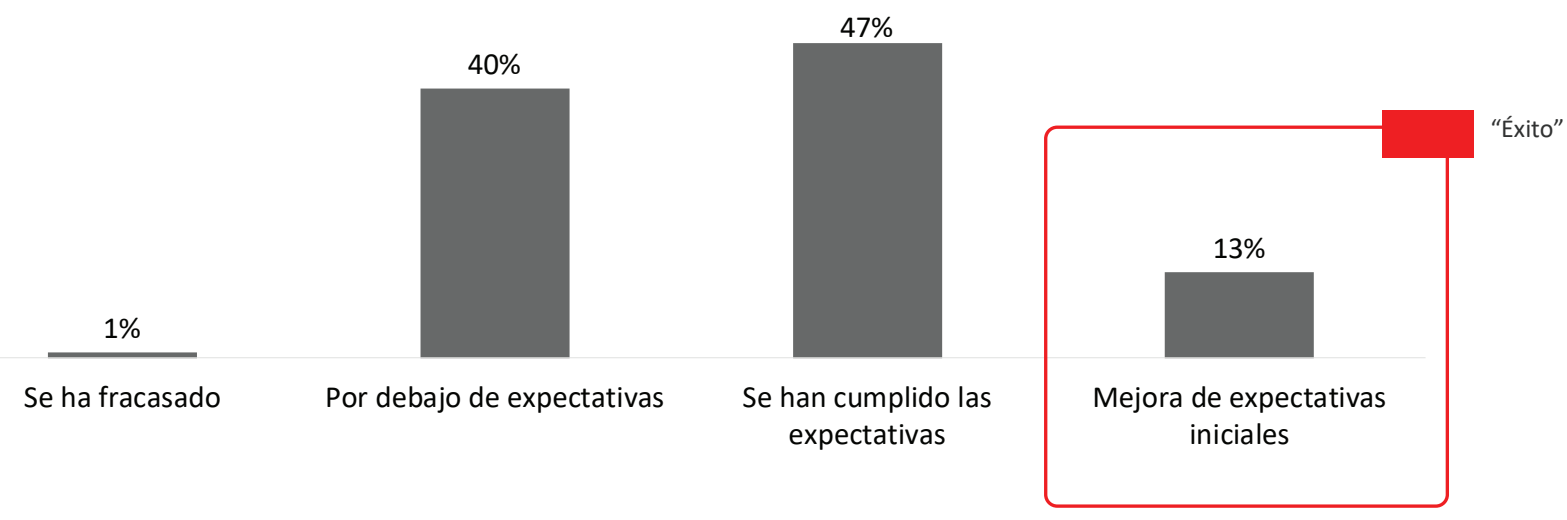

Por otro lado, el éxito es algo más plausible en empresas con mayores recursos que en aquellas con menor capacidad de inversión, reflejándose este aspecto en el hecho de que, a medida el tamaño de la compañía es mayor, hay también un mayor número de directivos que, como mínimo, han cumplido con los objetivos planteados inicialmente. Así, según los datos obtenidos, casi un 70\% de las compañías de más de 500 millones de euros de facturación anual lo han conseguido; algo más de un $60 \%$ de las de entre 250 y 500 millones; y, aproximadamente, el 50\% de las que facturan de 100 a 250 millones.

También se observa que el éxito llega más bien pronto: la mayoría de las empresas a las que les ha ido bien con la estrategia de transformación digital consiguen alcanzar el éxito entre el primer y el segundo año del programa, y hay un significativo segundo grupo de compañías que ha tardado entre dos y tres años. 


\section{Figura 4. Plazo en el que se materializa el éxito}

Pregunta: ¿Cuánto tiempo ha tardado en su compañía en tener resultados tangibles como consecuencia de la implementación y ejecución de un programa de transformación digital?

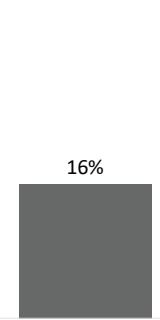

Menos de 1 año

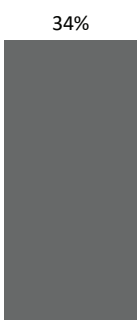

Entre 1 y 2 años

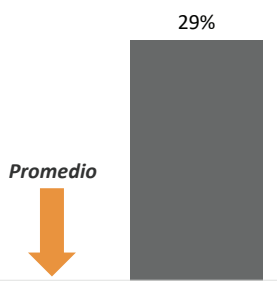

Entre 2 y 3 años

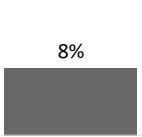

Mas de 3 años
$13 \%$

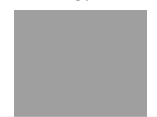

No ha sido posible obtener resultados tangibles

Todo ello induce a pensar a que existe un claro enfoque hacia iniciativas del tipo quick win, que inicialmente tienen un objetivo temporal de un máximo de dos años, pero que, si se retrasan, acaban en el rango de dos a tres años. 


\section{Capacidades tecnológicas disponibles}

Las capacidades que el mercado pone a disposición de las empresas son muchas, pero las que realmente se adoptan y están disponibles para ellas son más limitadas. En concreto, cabe diferenciar entre los siguientes tipos:

1. Capacidades transaccionales: ERP - Finanzas; ERP - Producción; CRM (customer relationaship management); HCM (human capital management); y SCM (supply chain management). Se incluyen la mayoría de los sistemas transaccionales que dan respuesta a actividades administrativas y de gestión de las diferentes funciones del negocio.

2. Capacidades de interconexión: Arquitecturas de integración entre sistemas internos (API internas) o con sistemas externos (API externas).

3. Capacidades analíticas: Analítica descriptiva/reporting y analítica avanzada (predicción de patrones, etc.).

4. Capacidades transversales: Cloud SaaS, Cloud laaS, redes sociales internas, redes sociales externas (clientes/proveedores), plataformas de automatización, inteligencia artificial (IA) aplicada a la analítica de datos, Internet of Things (IoT), IA-chatbots, IA-visión artificial y blockchain.

Es Las empresas siguen volcando una gran parte de los esfuerzos y recursos en los sistemas transaccionales, pero todavía quedan algunos deberes por hacer.

\section{Figura 5. Capacidades transaccionales}

Pregunta: Indique su nivel de adopción de los siguientes sistemas transaccionales. Valorada de 1 "No dispongo" a 3 "Sí, para la mayoría de procesos".

\begin{tabular}{|c|c|c|c|c|c|}
\hline \multirow{2}{*}{$\begin{array}{l}\| \text { No dispongo } \\
\text { ERP - Finanzas }\end{array}$} & \multicolumn{2}{|c|}{$\square \mathrm{Si}$, solo procesos concretos } & \multicolumn{2}{|c|}{ - Sí, para la mayoría de procesos } & \\
\hline & $13 \%$ & $19 \%$ & \multicolumn{3}{|c|}{$69 \%$} \\
\hline ERP - Producción & \multicolumn{2}{|c|}{$31 \%$} & $14 \%$ & \multicolumn{2}{|c|}{$56 \%$} \\
\hline CRM (customer relationship management) & $18 \%$ & & $36 \%$ & \multicolumn{2}{|c|}{$46 \%$} \\
\hline HCM (human capital management) & \multicolumn{3}{|c|}{$45 \%$} & $32 \%$ & $23 \%$ \\
\hline SCM (supply chain management) & \multicolumn{3}{|c|}{$47 \%$} & $31 \%$ & $22 \%$ \\
\hline
\end{tabular}

Los directivos tienen la percepción de que están mejor cubiertos sus procesos de soporte corporativo (Administración, Finanzas, Recursos Humanos) que aquellos que conforman la cadena de valor (Marketing y Clientes, Producción y Cadena de Suministro). Estos últimos están débilmente cubiertos por tecnología, hecho que se refleja en el relativamente bajo nivel de adopción de sistemas como el ERP-Producción, CRM y SCM. 
Figura 6. Los procesos core en la cadena de valor están débilmente cubiertos por tecnología

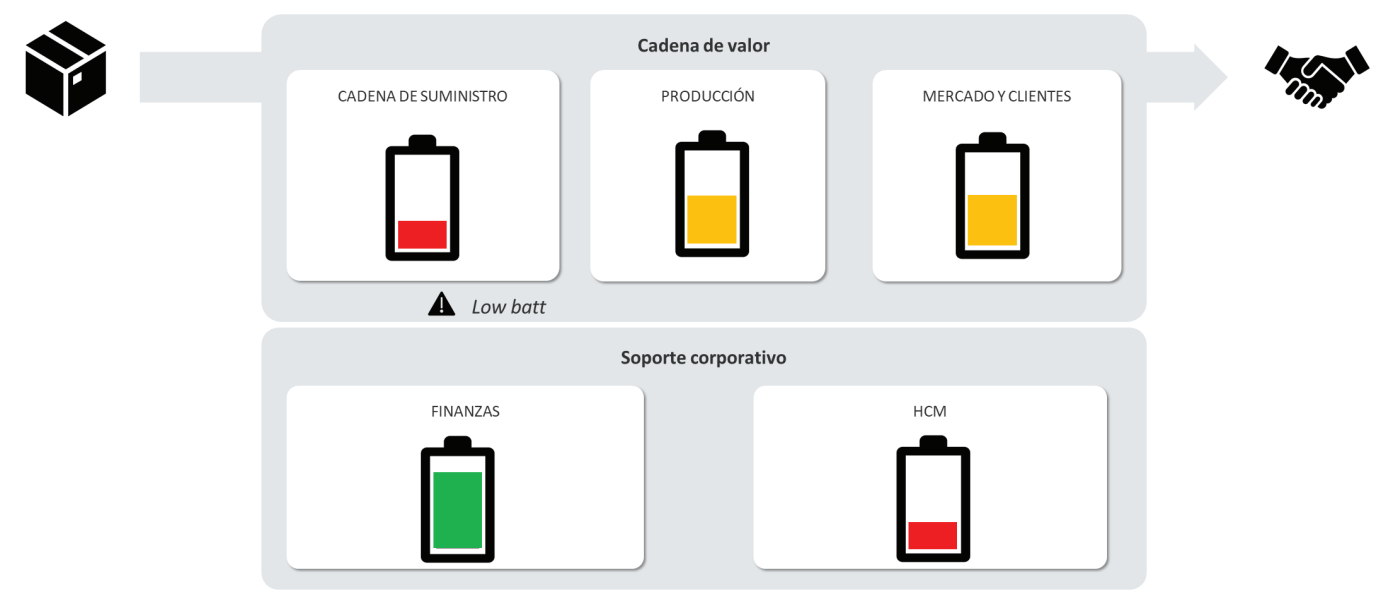

En cuanto a la presencia de arquitecturas modulares que permitan la interconexión de sistemas internos de las compañías o la interconexión con sistemas externos (proveedores o clientes, entre otros), la situación es muy mejorable, pues solo aproximadamente la mitad de las empresas disponen de estas capacidades; el resto, no. Estas arquitecturas permiten la integración de procesos entre la empresa y terceros, habilitando así su conexión con el ecosistema digital.

\section{Los datos son estratégicos, pero las capacidades analíticas son limitadas}

Los directivos son contundentes con la criticidad que les otorgan a los datos. Así, el $94 \%$ los considera estratégicos, otorgándoles la categoría de "activo fundamental" para generar la propuesta de valor para su compañía. Sin embargo, las empresas están lejos de conseguir que los datos sean efectivamente tratados como "activo".

\section{Figura 7. El valor de la información}

Pregunta: ¿Considera que los datos son un activo fundamental para generar la propuesta de valor (oferta) de su empresa? Valorada como "Sí" o "No".

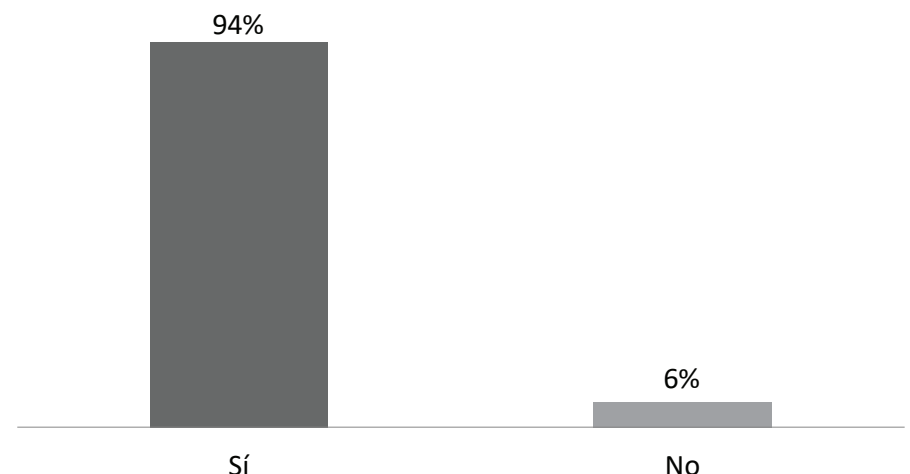

El 94\% de los directivos considera estratégicos a los datos, pero solo un $35 \%$ cree que dispone de soluciones para analítica descriptiva y un $10 \%$

las tiene para analítica predictiva, para todas las áreas. 
Figura 8. Capacidades analíticas

Pregunta: Indique su nivel adopción de analytics y big data.

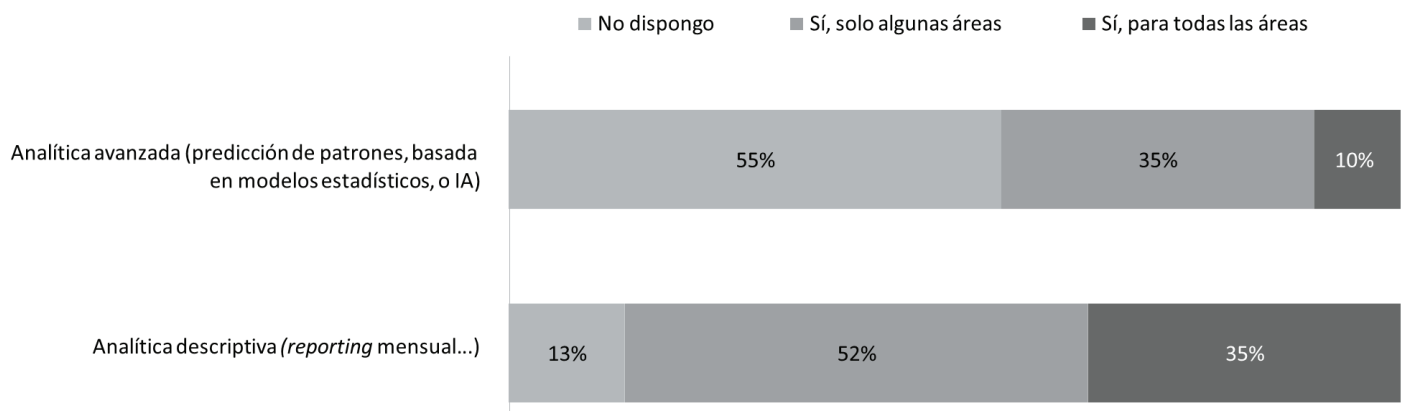

A la luz de otros estudios de Penteo, creemos que, detrás de estos datos, hay una realidad subyacente: la inversión no ha estado al nivel de lo indicado en el punto anterior y todavía hay importantes carencias en las capacidades analíticas de las compañías. Lamentablemente, en este caso no se trata solo de tecnología, ya que es necesario que las iniciativas de implantación y desarrollo de plataformas de analítica vayan acompañadas de un ambiciosa y decidida voluntad de establecer un modelo de gobierno dedicado al dato (data governance) y que asegure que la empresa esté orientada a este.

\section{El cloud está dejando de ser un factor de diferenciación positiva}

En los datos recabados, comprobamos que el cloud está presente en casi el $80 \%$ de las compañías (SaaS, laas), de modo que ha pasado a ser una capacidad que podemos considerar "madura" y, como tal, poco diferenciadora.

\section{Estamos en un punto en el que lo destacable (negativamente) es no haber iniciado la adopción de capacidades cloud de forma decidida.}

Otras tecnologías emergentes y transversales están todavía en fase de adopción en algunas compañías e, incluso, sin adopción en una mayoría. Estas tecnologías empezarán a permitir que las empresas sean más competitivas y generarán una mayor diferenciación con sus iguales, pero a medio y largo plazo.

Figura 9. Tecnologías consolidadas y no consolidadas

Pregunta: Indique si ha adoptado las siguientes tecnologías. Valorada en porcentajes de respuesta "Sí".

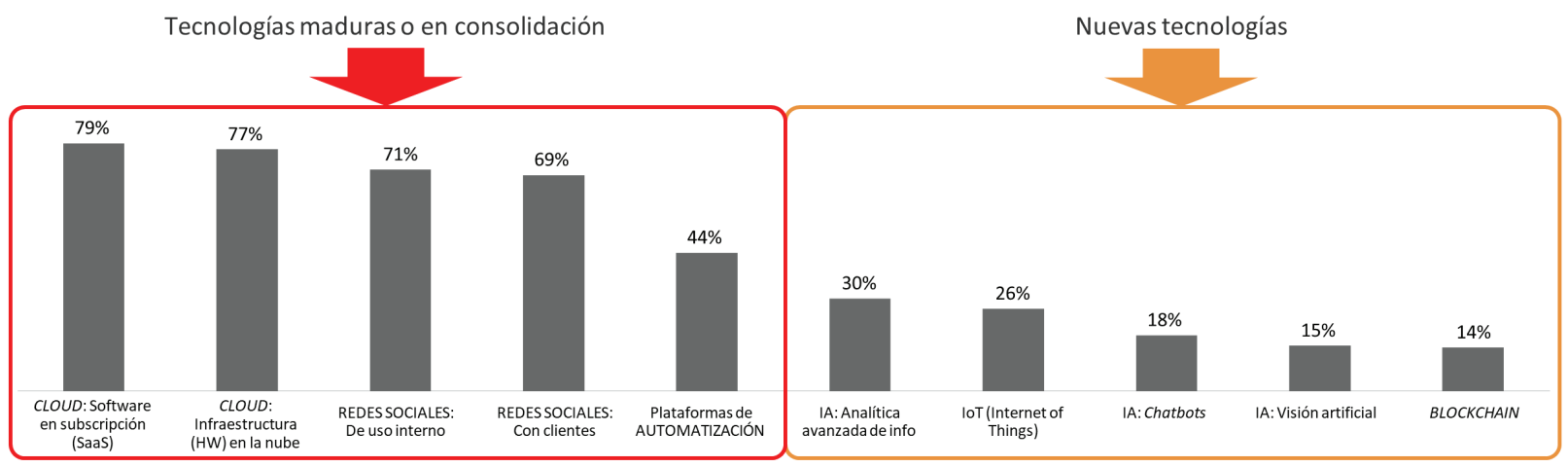




\section{Algunas tecnologías sí diferencian a las empresas por su éxito}

El resultado en cuanto a la adopción de tecnologías ofrece diferencias significativas en el grupo de directivos de empresas "con éxito" en la transformación digital; en estas, la adopción del ERP Producción y el CRM son superiores al resto.

También es notablemente superior la presencia de API externas, en concreto, entre 10 y 20 puntos más, así como la de tecnologías de analítica (tanto descriptiva como predictiva).

Las tecnologías transversales que más están diferenciando a las empresas "con éxito" del resto son las plataformas de automatización, que están presentes en el grupo con éxito en un 57\% (mientras que, en el grupo global, solo lo están en un 44\% de las compañías); las redes sociales con clientes, con un $87 \%$ de presencia en el grupo de mucho éxito (frente a solo un 69\% del grupo global); y la inteligencia artificial aplicada a la analítica avanzada de información, que está presente en un $71 \%$ de las empresas de más éxito transformador (y solo en un 30\%, en el grupo global).

\section{Figura 10. Tecnologías destacadas en las empresas de éxito}

Indique si ha adoptado las siguientes tecnologías. Valorada en porcentajes de respuesta "Si". Segmentadas según cumplimiento de expectativas (Q26).

- Todos "Grupo de "éxito"

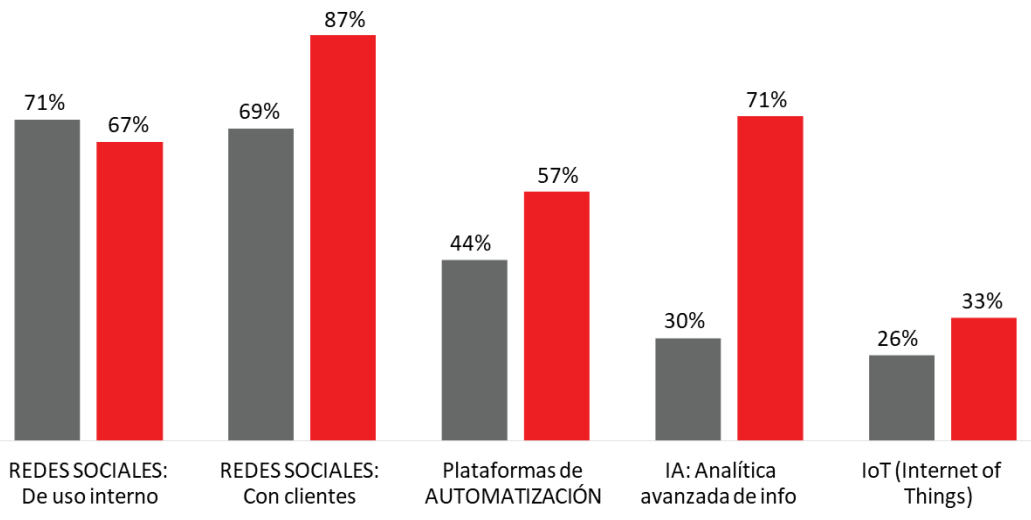

Así pues, la IA aplicada a la analítica avanzada de datos parece completamente determinante y diferencial entre las empresas. Debemos considerar, además, que la aplicación de IA (o simplemente de sistemas avanzados de analítica), en nuestra opinión, no se enfrenta a especiales barreras económicas si ya se dispone de ciertas capacidades y plataformas tecnológicas para la analítica de datos, así como de un modelo de gobierno del dato mínimamente desarrollado. 
Figura 11. Adopción de IoT por sectores

Pregunta: Indique si ha adoptado tecnologías de loT. en porcentajes de respuesta "Si".

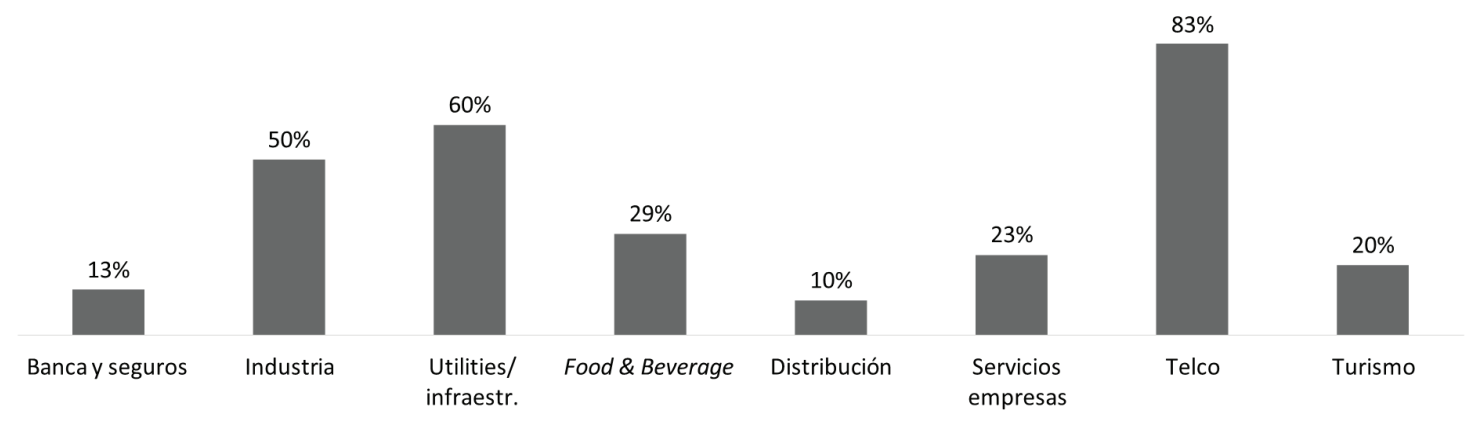

Por su parte, el loT es una tecnología también determinante, aunque más limitada en sectores industriales o donde hay infraestructuras y activos físicos estratégicos. En cuanto a las redes sociales de uso interno, resultan poco claves.

\section{Las prioridades de inversión -en busca del éxito- pasan por analytics, cloud e inteligencia artificial.}

En opinión de Penteo, las prioridades de inversión de las empresas que quieran aprovechar la tecnología disponible deberían tener mayor peso en analytics, cloud (si es que aún no lo han desarrollado) e IA, a medio-largo plazo. La inversión en capacidades transaccionales solo resulta diferencial si esta se dirige a las funciones de la cadena de valor (Logística, Relación con Clientes), pero no al resto. 


\section{Entorno competitivo}

El entorno competitivo se endurece para la mayoría de las compañías: un 71\% de ellas considera que han aparecido nuevos competidores en su sector. Esto afecta tanto a las empresas grandes como a las pequeñas, no hay distinciones significativas en esta percepción. Podemos clasificar a los nuevos competidores en tres categorías:

- Tradicionales: empresas que ya operaban en el mismo sector y que son percibidas por la compañía como un competidor con el que ya compartía mercado.

- Disruptivos/startups: startups tecnológicas o empresas de reciente creación que empiezan a operar en el mismo sector ofreciendo, normalmente, una oferta a clientes limitada pero atractiva.

- Disruptivos/tradicionales: compañías que operaban en otro sector (ya establecidas), pero que han logrado entrar en el mismo sector con una oferta a clientes atractiva.

\section{El asalto de empresas tradicionales hacia otros sectores tiene muchas barreras.}

La competencia proviene, principalmente, de actores tradicionales (ya presentes en el mismo sector) o startups, y no tanto de empresas preestablecidas de otros sectores. Esto induce a pensar que la transformación del modelo de negocio en un incumbente es altamente compleja y que la mayoría de las ventajas competitivas que se generan mediante la transformación digital se aprovechan en su mercado tradicional y no en nuevos negocios: la entrada en nuevos sectores de actividad se encuentra con muchas barreras.

\section{Figura 12. Origen de los competidores}

Pregunta: ¿En los últimos años han aparecido nuevos competidores en su sector? ¿Qué tipo de competidores? Valorada en porcentajes de respuesta "Sí" y según tipología.

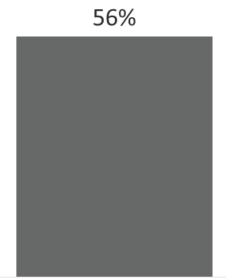

Tradicionales

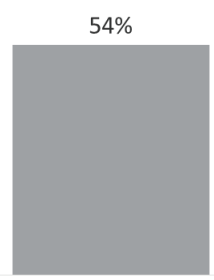

Disruptivos: startups
$30 \%$

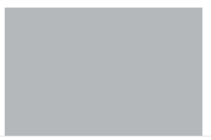

Disruptivos: empresas tradicionales de otros sectores 


\section{Cambios en los modelos de negocio}

Los modelos de negocio se ven afectados por el uso de la tecnología desde varios puntos de vista: la automatización, la personalización a clientes, la coordinación con terceros y la anticipación derivada de disponer de una mayor cantidad de datos de mayor riqueza.

\section{Figura 13. Modelo de negocio}

Pregunta: ¿En qué medida su modelo de negocio se ve afectado por el uso de la tecnología para [...]? Valorada en porcentaje.

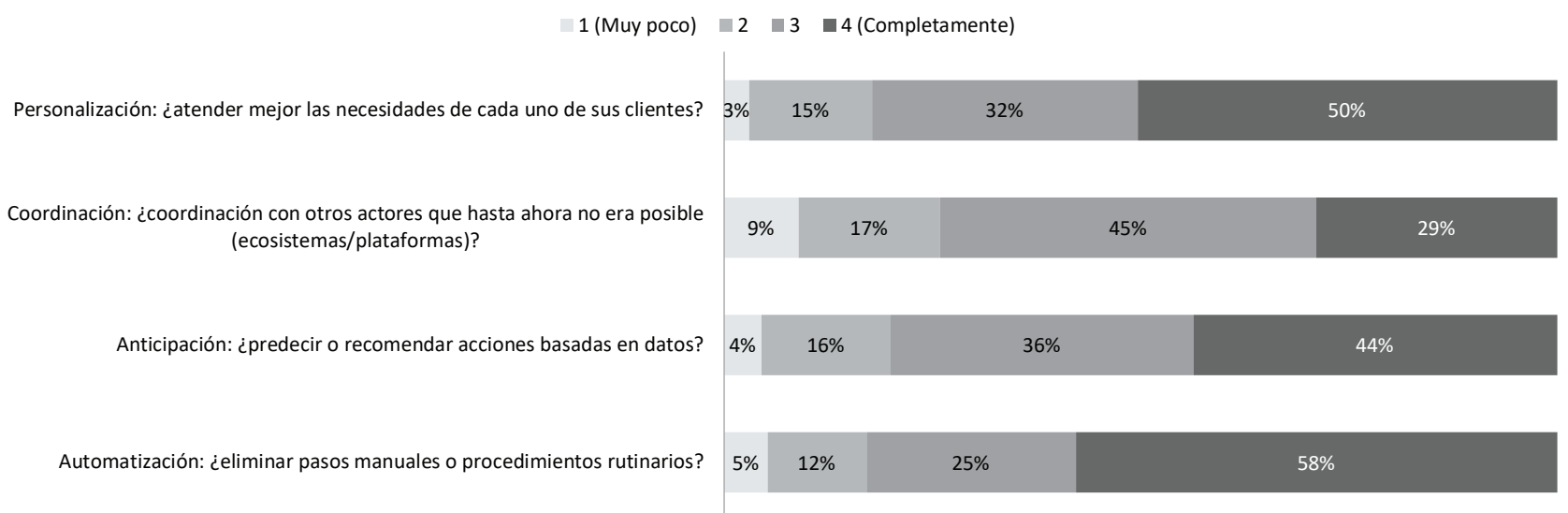

El uso de la tecnología para la automatización de procesos es la base de muchos modelos de negocio, al eliminar pasos manuales o procedimientos rutinarios, así como permitir personalizar, facilitando atender mejor las necesidades de cada cliente.

Sin embargo, la anticipación tiene, todavía, barreras importantes (tal como se puede derivar de la baja capacidad analítica avanzada de los datos) en relación con el desarrollo de una estrategia en torno al valor de aquellos o para hacer que la compañía sea data-driven. Por último, la coordinación con terceros actores a través de plataformas y ecosistemas no es mayoritaria en las empresas encuestadas, que siguen operando en cadenas de valor lineales en su sector.

\section{La mayoría de las empresas (87\%) que ha tenido éxito con su transformación digital ha modificado su estructura de costes y un $67 \%$ ha reducido el coste de servir a cliente.}

\section{Figura 14. Los costes en las empresas de éxito}

Izq. Pregunta: ¿Se han producido cambios en su estructura de costes? (En porcentajes de respuesta "Si"). Segmentadas según cumplimiento de expectativas (Q26).

Dcha. Pregunta: ¿Se ha reducido el coste de servir a un cliente? (En porcentajes de respuesta "Si"). Segmentadas según cumplimiento de expectativas (Q26).

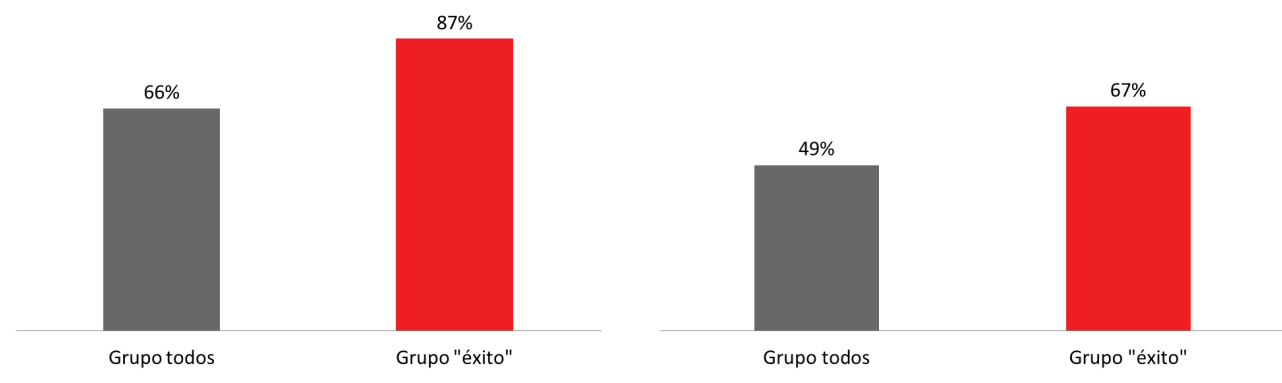


Resulta claro que los modelos de negocio deben cambiar como resultado de la transformación digital, pero, ¿hasta qué punto se está produciendo ese cambio?

En lo que respecta a los costes, los directivos que más reconocen haberse beneficiado de cambios en la estructura de aquellos son los de las empresas de "éxito" (un 87\% respecto a un 66\% de todas las empresas), además de haber experimentado una reducción en los costes del servicio (de en un $67 \%$ en las empresas "de éxito" frente a un $49 \%$ del todas las empresas).

Mejorar la estructura de costes general parece haber sido más sencillo que mejorar los márgenes de contribución de los servicios, consistente con la mayor apuesta tecnológica en procesos de soporte que en los de la cadena de valor en las compañías.

En lo que respecta a las fuentes de ingresos, estas sí han sufrido cambios para algunas empresas, en especial para las que han tenido éxito. Es de esperar que el éxito genere, a su vez, nuevas fuentes de ingresos, que no están al alcance de cualquier programa de transformación digital; muchas compañías, si bien cumplen con los objetivos marcados en la transformación digital, no llegan a percibir cambios significativos en las fuentes de ingresos.

\section{La modificación de las fuentes de ingresos no está al alcance de todos y es un auténtico reto de la transformación digital.}

A su vez, los KPI de negocio se definen de forma diferente según el grado de éxito de las empresas en su estrategia de transformación digital: en las de mayor éxito, en un 69\% de los casos hay KPI diferenciados para el negocio tradicional y el negocio emergente, mientras que en el conjunto de las empresas este es del 58\%.

\section{Figura 15. Definición de KPIs en las empresas de éxito}

Pregunta: ¿Hay distintos KPI entre el modelo de negocio emergente y el tradicional? Valorada en porcentajes de respuesta "Sí". Segmentadas según cumplimiento de expectativas (Q26).

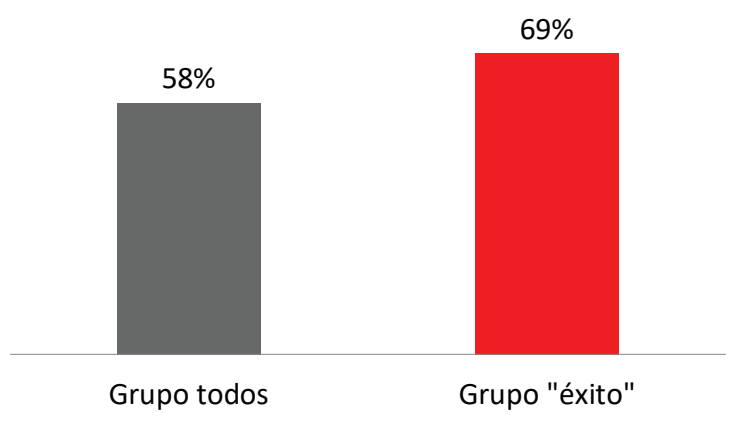




\section{Liderazgo y organización de la transformación digital}

La estrategia de transformación digital está liderada por la Dirección General de la empresa y el segundo nivel con mayor relevancia es la dirección de Sistemas. Las áreas funcionales se involucran, sobre todo cuando las iniciativas les afectan directamente.

Esta polarización del liderazgo (altamente concentrado en la figura del director general o CEO) se acentúa todavía más en las compañías que han tenido éxito con la transformación digital. Este efecto, además, se alinea con el hecho de que el apoyo de la dirección se considera unas de las condiciones clave para que la estrategia de transformación sea exitosa.

\section{Figura 16. Liderazgo de la transformación digital en las empresas de éxito}

Pregunta: ¿Qué unidad impulsa y lidera el proceso de transformación digital en su empresa? Segmentadas según cumplimiento de expectativas (Q26).

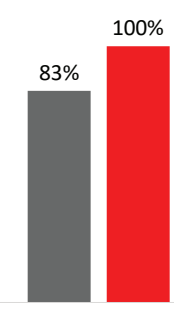

Dirección General

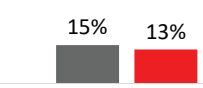

Área funcional (aparte Dirección de Sistemas o del área de tecnología)
- Todos " Grupo "éxito"

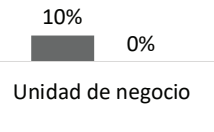

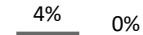

Organización híbrida independiente

$11 \% \quad 7 \%$
Otra. indicar:

El modelo de gobierno existente en las empresas para impulsar la estrategia de transformación se basa en una organización tradicional, donde tienen cabida la estrategia y las operaciones del día a día junto con programas estratégicos digitales. Son pocas las compañías (tan solo un 7\%) que reconocen disponer de estructuras híbridas, es decir, impulsando la transformación digital de forma separada del la operación del negocio.

Por otro lado, también son prácticamente testimoniales las empresas que disponen de una separación jurídica para las iniciativas más transformadoras (por ejemplo, entidades con una vocación de venture capital, impulsando viveros de startups, o con una estructura propia dedicada exclusivamente a la innovación). En concreto, este último modelo de liderazgo solo lo tienen un 2\% de compañías.

\section{La Dirección General lidera, mayoritariamente, el proceso de transformación digital y el segundo nivel con mayor peso es la dirección de Sistemas.}

Prácticamente todas las empresas han necesitado incorporar nuevas capacidades para apoyar la transformación digital y tres son las aproximaciones para ello: la generación de nuevas habilidades y conocimientos a través de programas de formación interna, el establecimiento de alianzas estratégicas con proveedores con los que poder desarrollar proyectos innovadores y la contratación de talento en plantilla para cubrir las necesidades de nuevas habilidades y conocimiento. 
Figura 17. Incorporación de capacidades nuevas

Pregunta: En caso de haber sido necesario incorporar nuevas capacidades en la empresa, ¿qué fuentes ha utilizado para ello?

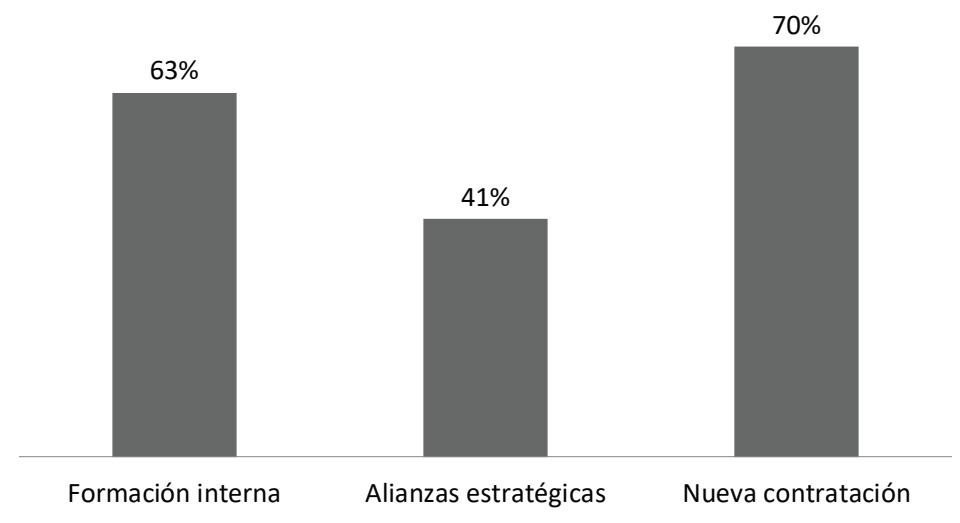

Las empresas, en general, apuestan más por la incorporación de nuevo talento (70\%) y la formación interna (63\%) que por el establecimiento de alianzas estratégicas (41\%). Sin embargo, las que han implementado programas de transformación digital con mayor éxito han apostado, en mayor medida, por el desarrollo de habilidades y conocimiento mediante formación interna (un 92\% de ese grupo, tal como puede observarse en el siguiente gráfico).

\section{Figura 18. Incorporación de capacidades nuevas en las empresas de éxito}

Pregunta: En caso de haber sido necesario incorporar nuevas capacidades en la empresa, ¿qué fuentes ha utilizado para incorporarlas? En porcentajes, segmentadas según cumplimiento de expectativas (Q26).

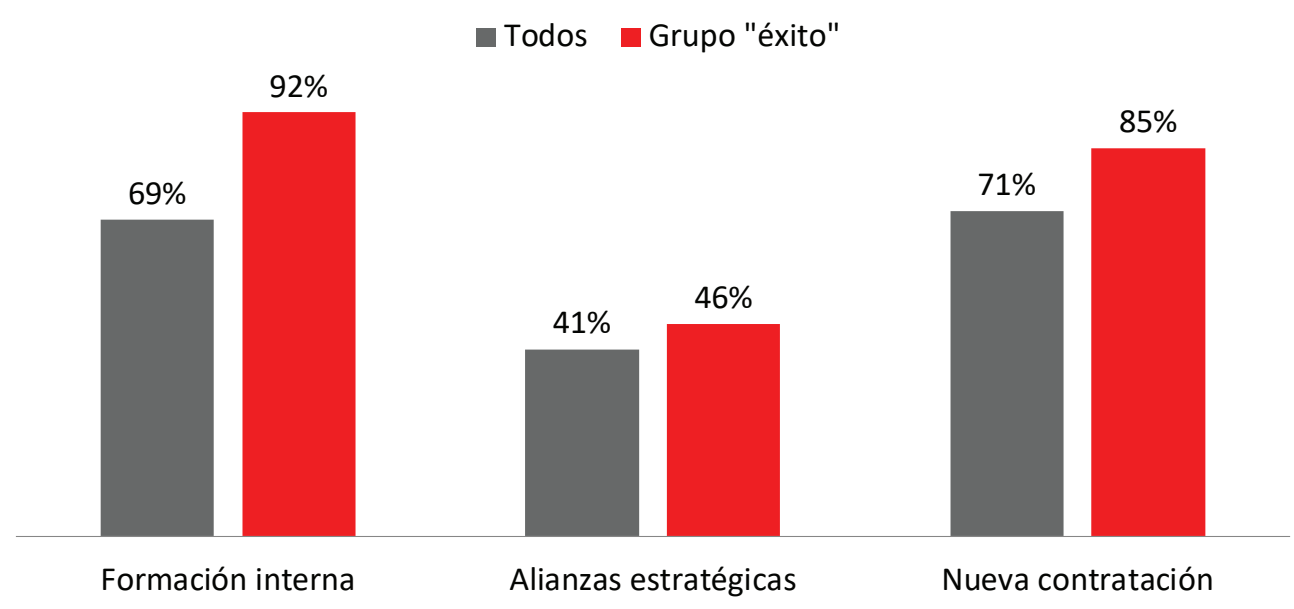

Las estructuras organizativas también se adaptan a los requerimientos de la transformación digital, si bien no parece resultar tan clave como la incorporación de nuevo talento. De hecho, solo un 54\% la ha modificado y entre el grupo de empresas de éxito este porcentaje crece ligeramente, hasta el 60\%. 
Figura 19. Cambios culturales y estructurales en las empresas de éxito

Izq. Pregunta: ¿Ha cambiado la estructura organizativa de su organización?

Dcha. Pregunta: ¿Ha cambiado la cultura de su organización?

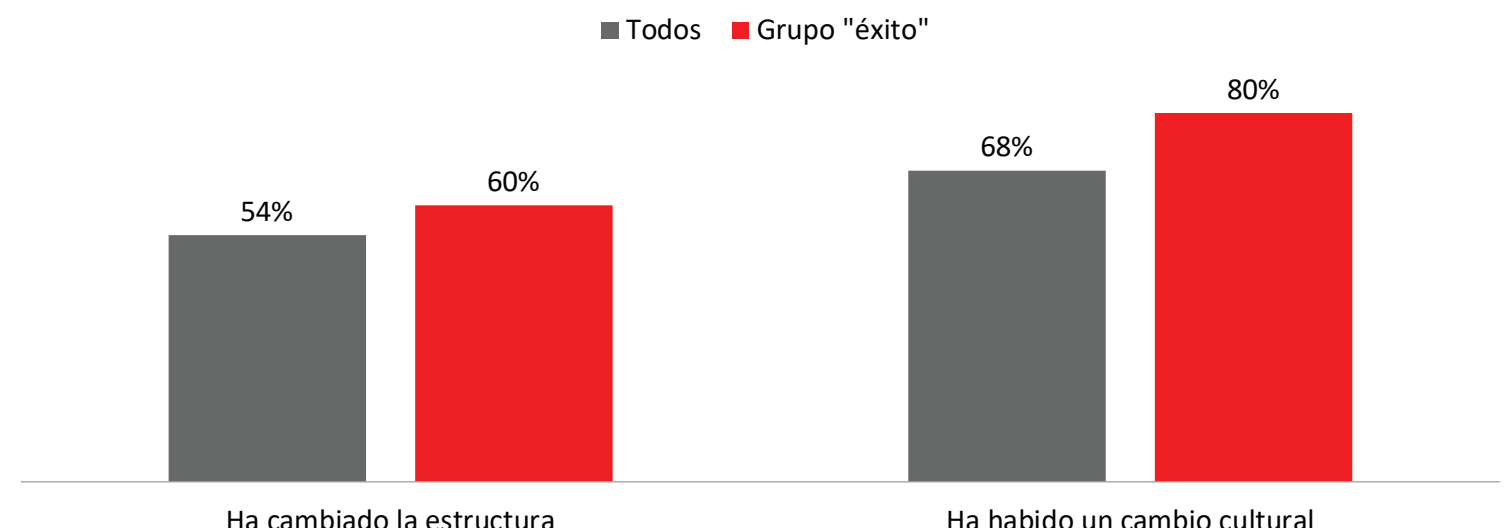

Más decisivo todavía es el cambio cultural de las compañías, puesto que se ha producido en un $68 \%$ del total y, en el caso concreto de las empresas con más éxito en su estrategia de transformación digital, este porcentaje se eleva hasta el $80 \%$.

La incorporación de nuevas capacidades y el cambio cultural son claves para el éxito de la transformación. El cambio de estructuras es importante, pero no es clave. 


\section{Mejores prácticas para la innovación}

Las empresas disponen de diferentes metodologías a su alcance para organizar su estrategia e impulsar la innovación, algunas tradicionales y no necesariamente asociadas a la actividad innovadora, y otras más enfocadas a la rápida generación y conceptualización de pilotos exploratorios para demostrar la viabilidad de despliegue de una tecnología novedosa. Entre otros métodos o procesos se han evaluado los siguientes:

- Open innovation: implica la participación y/o coordinación de terceros actores (externos a la compañía) en el proceso de innovación e inversión (clientes, proveedores, startups, etc.).

- Cocreación de valor: busca la creación de valor mediante un acercamiento y apertura del diálogo tanto con los clientes como con los empleados y proveedores para hacerlos partícipes en la definición de sus interacciones con la empresa.

- Deep-dive o inmersión profunda: consiste en sumergir rápidamente a un grupo o equipo de personas en una situación de resolución de problemas o creación de ideas (brainstorming).

- Design thinking: persigue, mediante una definición inicial del problema, la implementación de soluciones, pero siempre con las necesidades de los usuarios/clientes en el núcleo conceptual de desarrollo. Integra cinco pasos: empatizar, definir, idear, prototipar y probar.

- Jobs to Be Done (JTBD): se basa en que los clientes no compran pensando en el producto en sí, sino para ayudar a solucionar algo ("los trabajos a ser hechos").

- Customer journey mapping: permite detectar, a través del trazado de un mapa de las etapas que recorre una persona desde que le sobreviene una necesidad hasta que compra, cuál de aquellas es la que genera mayor valor para la experiencia del cliente en su proceso de vinculación con la compañía.

- $\boldsymbol{A} / \boldsymbol{B}$ testing: consiste en desarrollar y lanzar dos versiones de un mismo elemento (producto/ servicio) y medir cuál funciona mejor.

- Planificación estratégica: se trata de un proceso sistemático de desarrollo e implementación de planes para alcanzar propósitos u objetivos concretos para empresa.

- Hackathon: permite la organización de eventos y experiencias colectivas para lograr, a través de la tecnología, un objetivo común (la resolución de problemas concretos de negocio). Normalmente está ligado a entornos de desarrollo y programación, pero no exclusivamente.

- Rapid prototyping: es el desarrollo y presentación a los usuarios de prototipos, en iteraciones relativamente rápidas, para lograr una versión de producto mínimo viable (PMV) lo antes posible.

Aunque la metodología más extendida sigue siendo la planificación estratégica (61\%), la práctica de innovación más extendida. Le siguen, por orden, el design thinking, la open innovation y el customer journey mapping.

Así pues, tal como puede observarse en el gráfico anterior, prácticamente la mitad de las empresas no utilizan metodologías para el impulso innovador y las que sí lo hacen se centran en las que permiten la generación de nuevas oportunidades con el ecosistema (open innovation) y la conceptualización de soluciones orientadas al cliente. Por el contrario, las prácticas orientadas a gestionar un ciclo de prototipado sostenido en la compañía no se utilizan tanto.

En realidad, muchas de las iniciativas (excepto la planificación estratégica) son muy efímeras en las empresas. Sirven para acompañar iniciativas concretas y con enfoque táctico, pero no están completamente desplegadas y asentadas. 


\section{Figura 2o. Utilización de modelos metodológicos en las empresas de éxito}

Pregunta: Indique si se han utilizado alguno de los siguientes modelos, metodologías o procesos para la transformación del modelo de negocio de la empresa. En porcentajes, segmentadas según cumplimiento de expectativas (Q26).

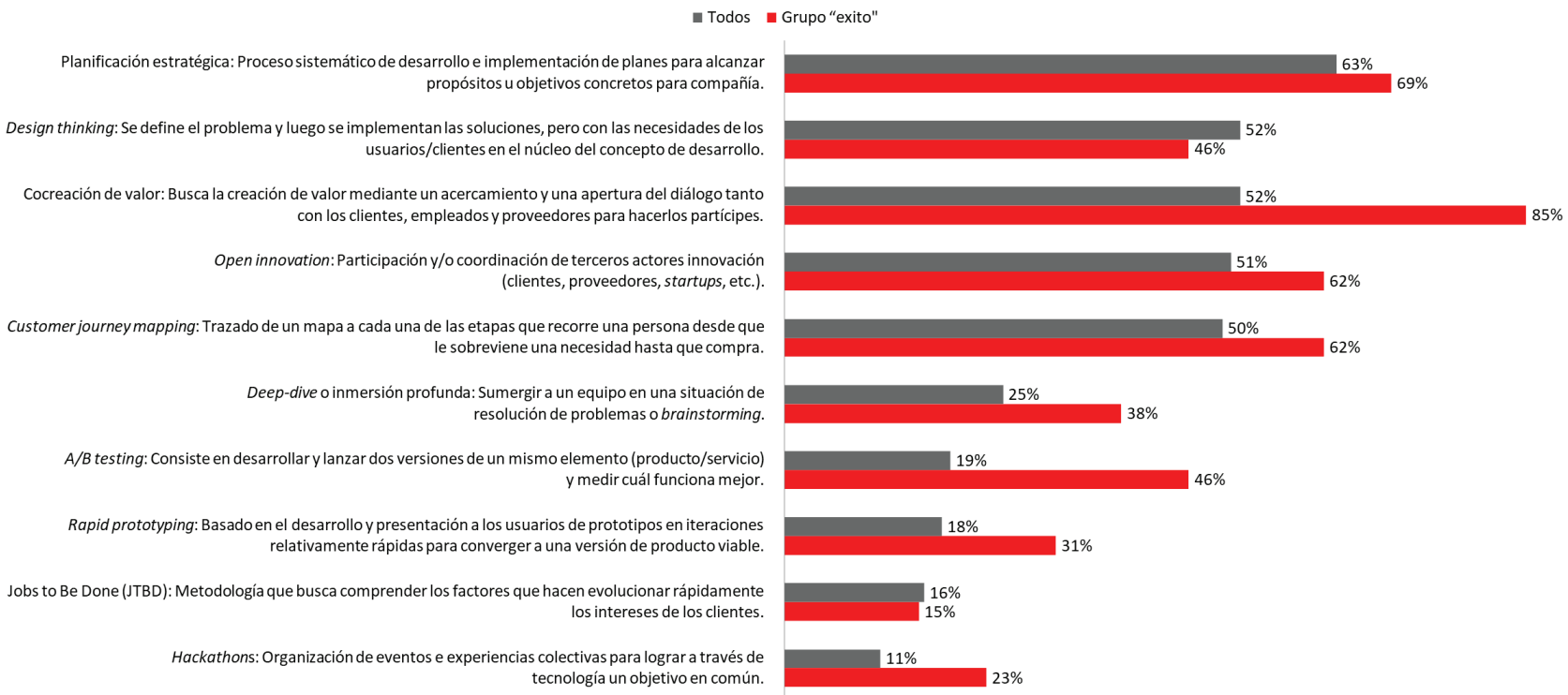

Las empresas de "éxito" destacan por haber llevado a cabo una mayor adopción de prácticas de experimentación como el A/B testing, los hackathons, la lean startups o el prototipado rápido. Significativamente, en la mayoría de las compañías encuestadas (75\%) coexisten las pruebas de concepto y pilotos con la ejecución del modelo de negocio tradicional. Sin embargo, la implantación de prácticas sistematizadas de aprendizaje es llamativamente superior entre las empresas "con éxito".

\section{Figura 21. Utilización de metodología de desarrollo en las empresas de éxito}

Pregunta: ¿Qué tipo de metodologías de desarrollo/construcción se utilizan en su empresa? En porcentajes, segmentadas según cumplimiento de expectativas (Q26).

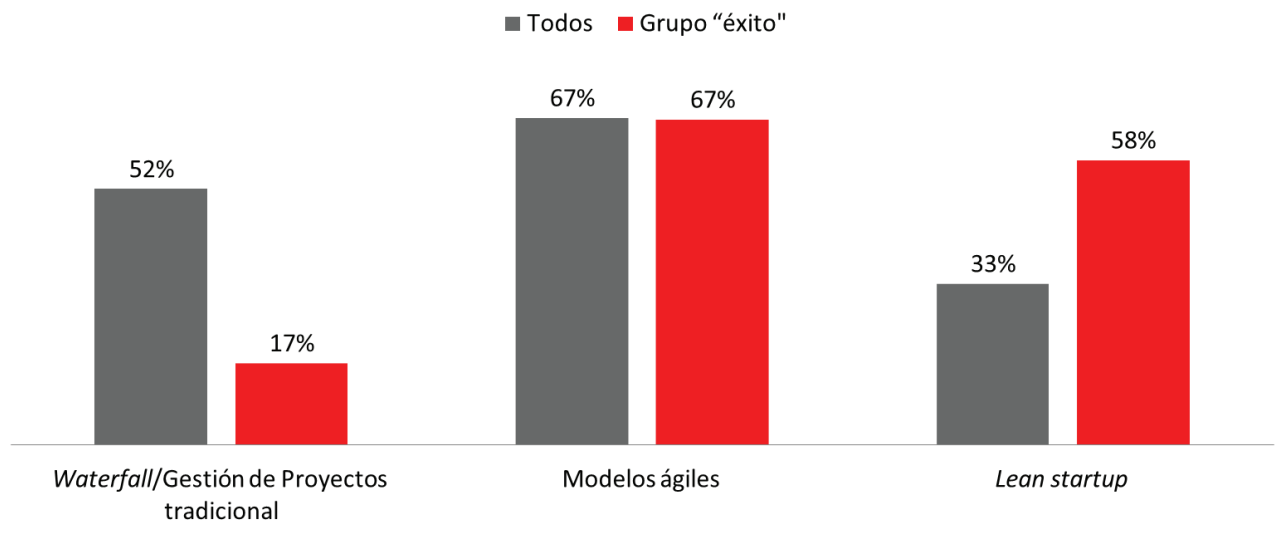

En un entorno tan cambiante como el actual, el desarrollo de productos y servicios requiere utilizar metodologías que permitan, en la medida de lo posible, un desarrollo incremental en distintas versiones que permitan validarlo rápidamente por parte del cliente y, de esta forma, minimizar el riesgo. Por este motivo, un $67 \%$ de las empresas encuestadas ya están implementando, en mayor o menor grado, metodologías de desarrollo agile como scrum o kanban. Sin embargo, cabe destacar que las metodologías tradicionales secuenciales como waterfall, que se basan en una planificación previa y una clara división de tareas (por ejemplo, diseño, arquitectura, implementación y testeo, etc.) solo las siguen utilizando el $17 \%$ de las compañías que declaran haber tenido éxito frente a una adopción media del $52 \%$ del total de las encuestadas. 


\section{Conclusiones}

\section{Transformación digital}

La transformación digital tiene muchos significados e incluye distintos aspectos en la mayoría de empresas. Sin embargo, aquellas "con éxito" por encima de las expectativas la asocian con una mayor agilidad del negocio ante un mercado cada vez más cambiante e impredecible, y tratan de extender la cultura innovadora a toda la compañía, de forma sostenible.

El dato se convierte en el principal activo de las empresas. Sin embargo, las compañías "con éxito" en la transformación digital son aquellas que utilizan el dato más allá de la automatización de procesos.

\section{Tecnología para el éxito}

Las capacidades tecnológicas que permiten diferenciar a las empresas con más éxito en ese viaje de transformación son:

- Invertir en ampliar y profesionalizar las capacidades analíticas, sobre todo avanzadas, incluyendo la analítica predictiva (IA).

- Disponer de arquitecturas abiertas que permitan conectar la compañía con terceros (API).

- Continuar apoyando con herramientas digitales los principales procesos de la cadena de valor, sobre todo los de contacto con su mercado, sus clientes y los que dan soporte a la cadena de suministro.

En cuanto a su clasificación, identificamos dos tipos de tecnologías: aquellas que han dejado de ser diferenciadoras y las que tienen más potencial para generar competitividad para las empresas que las adopten.

Entre las primeras, encontramos el cloud computing, que ha pasado a ser prácticamente una commodity y, en el caso de que la empresa no tenga suficiente desarrollo, puede suponer un lastre para su transformación digital. Entre las segundas, destacan las redes sociales de uso externo, las plataformas de automatización, las arquitecturas orientadas a la conectividad con terceros externos y, de manera muy especial, la inteligencia artificial aplicada a la analítica avanzada de información. Todas ellas deberían formar parte, en mayor o menor medida, de la estrategia digital de las compañías.

Si bien los datos se consideran estratégicos, las empresas están lejos de tener las capacidades analíticas necesarias para extraer el valor de ellos. No se cuenta con suficiente capacitación tecnológica y las tecnologías analíticas están todavía muy orientadas a unos pocos procesos y al mero reporting descriptivo.

\section{Impacto en los modelos de negocio}

El entorno competitivo se ha endurecido y, gracias al desarrollo de nuevas tecnologías, aparecen competidores, sobre todo de startups y compañías tradicionales que ya operan en el mismo sector. La migración de empresas tradicionales hacia sectores adyacentes es compleja y ahora parece encontrarse con más barreras.

Una parte del éxito en la innovación de modelos de negocio se refleja en una mejora del coste de servir a los clientes; sin embargo, la capacidad de generar nuevas fuentes de ingresos gracias a la transformación digital es todavía algo esquiva para la mayoría de las compañías. 


\section{Organización y liderazgo}

El liderazgo de la transformación digital está recayendo en el CEO y, si bien el director de Sistemas tiene un papel destacado entre el resto de directivos, su peso queda bajo el del CEO.

Prácticamente todas las empresas necesitan incorporar nuevas habilidades y conocimiento para avanzar en la transformación digital y la mayoría lo hacen apoyándose en programas de desarrollo interno (formación a empleados) junto con la incorporación de nuevos perfiles y talento.

Las compañías que avanzan con éxito por encima de las expectativas abordan cambios culturales (un 81\%) e incorporan nuevas capacidades con mayor intensidad, además de utilizar alianzas estratégicas.

La transformación digital supone una transformación holística en la adopción de las nuevas tecnologías, en la reformulación de los modelos de negocios, así como en la transformación de la organización, tanto en sus estructuras organizativas como en las metodologías de trabajo, la incorporación de nuevas capacidades y la buena gobernanza del dato.

La crisis de la COVID-19 está poniendo sobre la mesa la necesidad de priorizar algunos de los objetivos de la transformación digital. En concreto, en una situación como la actual, las empresas que hayan orientado sus programas de transformación digital hacia la mejora de la agilidad y una mayor capacidad de toma rápida de decisiones (de la mano de más capacidades de analítica) tendrán una mayor capacidad de reacción frente a clientes, proveedores y empleados.

La agilidad del negocio es fundamental para poder aprovechar al máximo los nichos de demanda y las nuevas necesidades que puedan generarse por el cambio de realidad. 


\section{Anexo I. Ficha técnica}

\section{Numero de directivos participantes: 207}

Periodo de la investigación: entre septiembre y octubre del 2019

\section{Sectores analizados}

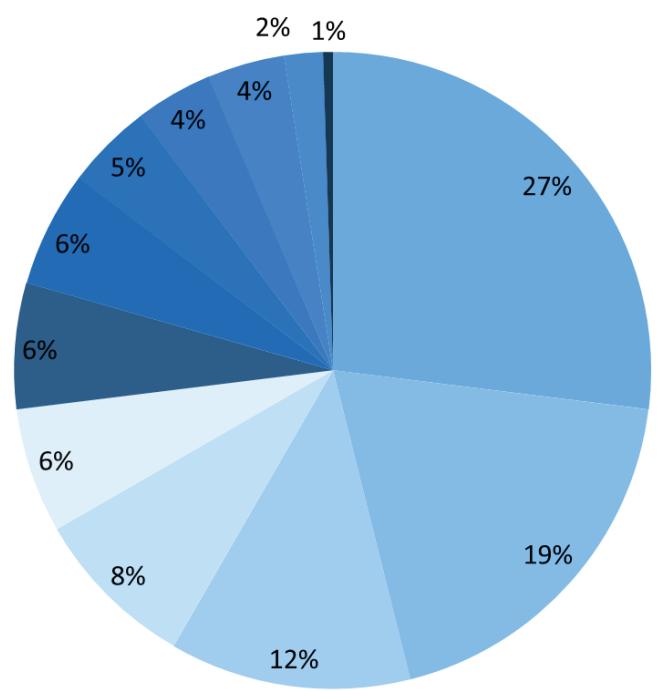

$$
\begin{aligned}
& \text { - Otro (especifique) } \\
& \text { Servicios a empresas } \\
& \text { Industria } \\
& \text { Food \& Beverage } \\
& \text { Banca y seguros } \\
& \text { - Sanitario/hospitalario } \\
& \text { - Distribución } \\
& \text { - Utilities e infraestructuras } \\
& \text { - Telco } \\
& \text { - Turismo } \\
& \text { - Sector público } \\
& \text { - Servicios públicos }
\end{aligned}
$$

Tamaño de las compañías analizadas

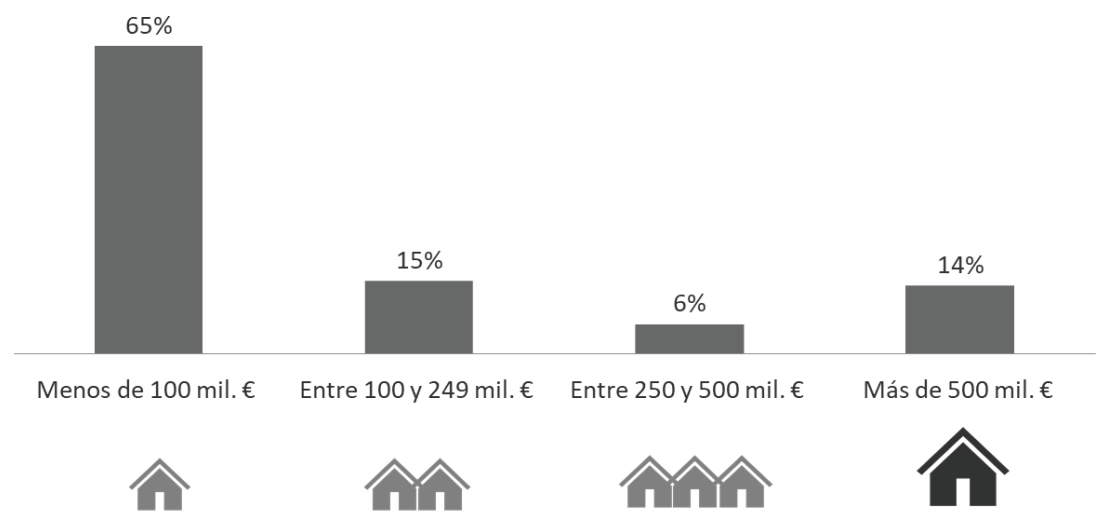




\section{Anexo II. Cuestionario de investigación}

Por cuestiones de privacidad, se han eliminado todas las preguntas abiertas del cuestionario, así como las respuestas aportadas.

\section{Q1. Sector de la compañía u organización}

\begin{tabular}{|l|c|}
\hline Opciones de respuesta & Respuestas \\
\hline Servicios a empresas & $19,12 \%$ \\
\hline Industria & $12,25 \%$ \\
\hline Food \& Beverage & $8,33 \%$ \\
\hline Banca y seguros & $6,37 \%$ \\
\hline Sanitario/hospitalario & $6,37 \%$ \\
\hline Distribución & $5,88 \%$ \\
\hline Utilities e infraestructuras & $4,41 \%$ \\
\hline Telco & $3,92 \%$ \\
\hline Turismo & $3,92 \%$ \\
\hline Sector público & $1,96 \%$ \\
\hline Servicios públicos & $0,49 \%$ \\
\hline Otro (especifique) & $26,96 \%$ \\
\hline
\end{tabular}

\section{Q2. Ingresos brutos en España}

\begin{tabular}{|l|c|}
\hline Opciones de respuesta & Respuestas \\
\hline Menos de 100 mill. $€$ & $65,22 \%$ \\
\hline Entre 100 y 249 mill. $€$ & $15,46 \%$ \\
\hline Más de 500 mill. $€$ & $14,49 \%$ \\
\hline Entre 250 y 500 mill. $€$ & $6,28 \%$ \\
\hline
\end{tabular}

\section{Q3. Número de empleados en España}

\begin{tabular}{|l|c|}
\hline Opciones de respuesta & Respuestas \\
\hline Menos de 50 empleados & $37,20 \%$ \\
\hline De 50 a 249 empleados & $24,15 \%$ \\
\hline De 250 a 1.000 empleados & $21,26 \%$ \\
\hline Más de 1.000 empleados & $17,87 \%$ \\
\hline
\end{tabular}




\section{Q4. Evalúe en qué medida...}

\begin{tabular}{|c|c|c|c|c|}
\hline & $\stackrel{1}{\text { (En absoluto) }}$ & 2 & 3 & $\begin{array}{l}4 \\
\text { (Completamente) }\end{array}$ \\
\hline $\begin{array}{l}\text {...el concepto de transformación } \\
\text { digital está afectando a su } \\
\text { organización }\end{array}$ & $3,16 \%$ & $13,92 \%$ & $27,85 \%$ & $55,06 \%$ \\
\hline $\begin{array}{l}\text {... la aparición de nuevas } \\
\text { tecnologías (móvil, tableta, } \\
\text { asistente de voz, etc.) ha } \\
\text { cambiado la relación con el } \\
\text { cliente }\end{array}$ & $6,96 \%$ & $18,99 \%$ & $36,71 \%$ & $37,34 \%$ \\
\hline
\end{tabular}

Q5. Indique su nivel de adopción de los siguientes sistemas transaccionales

\begin{tabular}{|l|c|c|c|}
\hline & No dispongo & $\begin{array}{c}\text { Sí, solo } \\
\text { procesos } \\
\text { concretos }\end{array}$ & $\begin{array}{c}\text { Sí, para la } \\
\text { mayoría de } \\
\text { procesos }\end{array}$ \\
\hline SCM (supply chain management) & $46,71 \%$ & $30,92 \%$ & $22,37 \%$ \\
\hline HCM (human capital management) & $44,81 \%$ & $32,47 \%$ & $22,73 \%$ \\
\hline CRM (customer relationship management) & $18,18 \%$ & $35,71 \%$ & $46,10 \%$ \\
\hline ERP - Producción & $30,52 \%$ & $13,64 \%$ & $55,84 \%$ \\
\hline ERP - Finanzas & $12,82 \%$ & $18,59 \%$ & $68,59 \%$ \\
\hline
\end{tabular}

Q6. Indique su nivel de adopción de analytics \& big data

\begin{tabular}{|l|c|c|c|}
\hline & No dispongo & $\begin{array}{c}\text { Sí, solo } \\
\text { algunas áreas }\end{array}$ & $\begin{array}{c}\text { Sí, para todas } \\
\text { las áreas }\end{array}$ \\
\hline Analítica descriptiva (reporting mensual...) & $12,99 \%$ & $51,95 \%$ & $35,06 \%$ \\
\hline Analítica avanzada (predicción de patrones...) & $55,19 \%$ & $35,06 \%$ & $9,74 \%$ \\
\hline
\end{tabular}

Q7. Indique si ha adoptado las siguientes tecnologías

\begin{tabular}{|l|l|l|}
\hline & Si & No \\
\hline CLOUD: software en subscripción (SaaS) & $79,22 \%$ & $20,78 \%$ \\
\hline CLOUD: infraestructura (HW) en la nube & $77,27 \%$ & $22,73 \%$ \\
\hline REDES SOCIALES: de uso interno & $70,78 \%$ & $29,22 \%$ \\
\hline REDES SOCIALES: con clientes & $69,08 \%$ & $30,92 \%$ \\
\hline Plataformas de AUTOMATIZACIÓN & $44,22 \%$ & $55,78 \%$ \\
\hline IA: analítica avanzada de info & $29,61 \%$ & $70,39 \%$ \\
\hline IoT (Internet of Things) & $26,35 \%$ & $73,65 \%$ \\
\hline IA: chatbots & $17,88 \%$ & $82,12 \%$ \\
\hline IA: visión artificial & $14,57 \%$ & $85,43 \%$ \\
\hline BLOCKCHAIN & $14,00 \%$ & $86,00 \%$ \\
\hline
\end{tabular}


Q8. ¿En su empresa la infraestructura tecnológica es modular utilizando API (application programming interface)?

\begin{tabular}{|l|l|l|}
\hline & Sí & No \\
\hline API internas & $53,06 \%$ & $46,94 \%$ \\
\hline API externas & $50,00 \%$ & $50,00 \%$ \\
\hline
\end{tabular}

Q9. Indique cuál sería la prioridad de inversión que le otorgaría a las siguientes tecnologías durante los próximos dos años:

\begin{tabular}{|c|c|c|c|c|}
\hline & $\begin{array}{c}1 \\
\text { (Baja) }\end{array}$ & 2 & 3 & $\begin{array}{c}4 \\
\text { (Alta) }\end{array}$ \\
\hline Sistemas transaccionales & $16,89 \%$ & $22,97 \%$ & $29,05 \%$ & $31,08 \%$ \\
\hline Cloud computing & $9,93 \%$ & $22,52 \%$ & $34,44 \%$ & $33,11 \%$ \\
\hline Redes sociales & $18,24 \%$ & $29,05 \%$ & $29,05 \%$ & $23,65 \%$ \\
\hline Analytics \& big data & $5,37 \%$ & $13,42 \%$ & $27,52 \%$ & $53,69 \%$ \\
\hline Inteligencia artificial & $19,73 \%$ & $21,09 \%$ & $26,53 \%$ & $32,65 \%$ \\
\hline loT & $30,41 \%$ & $33,11 \%$ & $20,95 \%$ & $15,54 \%$ \\
\hline Blockchain & $44,59 \%$ & $31,08 \%$ & $14,19 \%$ & $10,14 \%$ \\
\hline Plataformas de automatización & $18,37 \%$ & $23,13 \%$ & $29,25 \%$ & $29,25 \%$ \\
\hline $\begin{array}{l}\text { Hacer nuestra arquitectura más } \\
\text { modular (API) }\end{array}$ & $18,62 \%$ & $20,69 \%$ & $32,41 \%$ & $28,28 \%$ \\
\hline
\end{tabular}

Q10. Indique, para cada uno de estos factores, si considera que definen el concepto de "transformación digital"

\begin{tabular}{|l|c|c|c|} 
& Poco & Parcialmente & Completamente \\
\hline DIGITALIZAR/AUTOMATIZAR los procesos & $2,67 \%$ & $32,67 \%$ & $64,67 \%$ \\
\hline $\begin{array}{l}\text { Extender la INNOVACIÓN en la compañía } \\
\text { Implantar NUEVOS PROCESOS }\end{array}$ & $9,33 \%$ & $46,00 \%$ & $44,67 \%$ \\
\hline impensables sin la tecnología actual & $4,67 \%$ & $21,33 \%$ & $74,00 \%$ \\
\hline $\begin{array}{l}\text { COLABORACIÓN y compartición digital de } \\
\text { conocimiento }\end{array}$ & $3,31 \%$ & $29,14 \%$ & $67,55 \%$ \\
\hline $\begin{array}{l}\text { Mayor PRODUCTIVIDAD del puesto de } \\
\text { trabajo digital }\end{array}$ & $3,31 \%$ & $41,72 \%$ & $54,97 \%$ \\
\hline $\begin{array}{l}\text { Mayor AGILIDAD del negocio en cualquier } \\
\text { circunstancia }\end{array}$ & $5,33 \%$ & $31,33 \%$ & $63,33 \%$ \\
\hline $\begin{array}{l}\text { Disponer de SERVICIOS o PRODUCTOS } \\
\text { digitales }\end{array}$ & $11,33 \%$ & $37,33 \%$ & $51,33 \%$ \\
\hline $\begin{array}{l}\text { Tecnología para CONOCER mejor al } \\
\text { cliente y PERSONALIZAR la oferta }\end{array}$ & $2,65 \%$ & $28,48 \%$ & $68,87 \%$ \\
\hline $\begin{array}{l}\text { Acceso rápido de INFORMACIÓN para } \\
\text { anticiparnos en el mercado }\end{array}$ & $3,36 \%$ & $35,57 \%$ & $61,07 \%$ \\
\hline $\begin{array}{l}\text { Generar valor con NUEVOS MODELOS } \\
\text { de NEGOCIO }\end{array}$ & $7,28 \%$ & $25,17 \%$ & $67,55 \%$ \\
\hline
\end{tabular}


Q11. Evalúe en qué medida...

\begin{tabular}{|l|c|c|c|c|}
\hline & $\begin{array}{c}\text { 1 } \\
\text { (Poco o bajo) }\end{array}$ & 2 & 3 & $\begin{array}{c}4 \\
\text { (Mucho o alto) }\end{array}$ \\
\hline $\begin{array}{l}\text {...ha habido una transformación } \\
\text { digital disruptiva en su sector }\end{array}$ & $19,87 \%$ & $31,79 \%$ & $24,50 \%$ & $23,84 \%$ \\
\hline $\begin{array}{l}\text {...ha cambiado de forma } \\
\text { sustancial la interacción con sus } \\
\text { clientes }\end{array}$ & $12,58 \%$ & $39,07 \%$ & $29,80 \%$ & $18,54 \%$ \\
\hline $\begin{array}{l}\text {...considera que es el grado de } \\
\text { regulación en su sector }\end{array}$ & $21,85 \%$ & $25,83 \%$ & $20,53 \%$ & $31,79 \%$ \\
\hline
\end{tabular}

Q12. ¿Se prevén cambios regulatorios en su sector por la transformación digital?

\begin{tabular}{|l|c|}
\hline Opciones de respuesta & Respuestas \\
\hline Sí & $47,02 \%$ \\
\hline No & $52,98 \%$ \\
\hline
\end{tabular}

Q13. ¿En los últimos años han aparecido nuevos competidores en su sector?

\begin{tabular}{|l|c|}
\hline Opciones de respuesta & Respuestas \\
\hline Sí & $70,86 \%$ \\
\hline No & $29,14 \%$ \\
\hline
\end{tabular}

Q14. En caso afirmativo ¿qué tipo de competidores?

\begin{tabular}{|l|c|}
\hline Opciones de respuesta & Respuestas \\
\hline Tradicionales & $55,91 \%$ \\
\hline Disruptivos: startups & $53,54 \%$ \\
\hline $\begin{array}{l}\text { Disruptivos: empresas tradicionales } \\
\text { de otros sectores }\end{array}$ & $29,92 \%$ \\
\hline
\end{tabular}

Q15. Cuáles de estas opciones forman parte del modelo de negocio de su compañía

\begin{tabular}{|l|r|}
\hline Opciones de respuesta & Respuestas \\
\hline B2B & $81,20 \%$ \\
\hline B2C & $48,87 \%$ \\
\hline C2C & $5,26 \%$ \\
\hline
\end{tabular}


Q16. ¿La transformación digital va a suponer un cambio en el modelo de negocio?

\begin{tabular}{|l|c|}
\hline Opciones de respuesta & Respuestas \\
\hline Sí & $73,13 \%$ \\
\hline No & $26,87 \%$ \\
\hline
\end{tabular}

Q17. ¿En qué medida su modelo de negocio se ve afectado por el uso de tecnología para...?

\begin{tabular}{|c|c|c|c|c|}
\hline & $\begin{array}{c}1 \\
\text { (Muy poco) }\end{array}$ & 2 & 3 & $\begin{array}{l}4 \\
\text { (Completamente) }\end{array}$ \\
\hline $\begin{array}{l}\text {...automatización: eliminar pasos } \\
\text { manuales o procedimientos } \\
\text { rutinarios }\end{array}$ & $5,19 \%$ & $11,85 \%$ & $25,19 \%$ & $57,78 \%$ \\
\hline $\begin{array}{l}\text {....anticipación: predecir o } \\
\text { recomendar acciones basadas } \\
\text { en datos }\end{array}$ & $4,44 \%$ & $15,56 \%$ & $36,30 \%$ & $43,70 \%$ \\
\hline $\begin{array}{l}\text {...coordinación: coordinación con } \\
\text { otros actores que hasta ahora } \\
\text { no era posible (ecosistemas/ } \\
\text { plataformas) }\end{array}$ & $8,89 \%$ & $17,04 \%$ & $45,19 \%$ & $28,89 \%$ \\
\hline $\begin{array}{l}\text {...personalización: atender mejor } \\
\text { las necesidades de cada uno de } \\
\text { sus clientes }\end{array}$ & $2,96 \%$ & $14,81 \%$ & $31,85 \%$ & $50,37 \%$ \\
\hline
\end{tabular}

Q18. ¿Considera que los datos son un activo fundamental para generar la propuesta de valor (oferta) de su empresa?

\begin{tabular}{|l|r|}
\hline Opciones de respuesta & Respuestas \\
\hline Sí & $93,98 \%$ \\
\hline No & $6,02 \%$ \\
\hline
\end{tabular}

Q19. ¿Se han producido cambios en cómo se construye la propuesta de valor?

\begin{tabular}{|l|c|}
\hline Opciones de respuesta & Respuestas \\
\hline Sí & $73,68 \%$ \\
\hline No & $26,32 \%$ \\
\hline
\end{tabular}


Q20. ¿Se han producido cambios en cómo se comercializa la propuesta de valor?

\begin{tabular}{|c|c|}
\hline Opciones de respuesta & Respuestas \\
\hline Sí & $75,94 \%$ \\
\hline No & $24,06 \%$ \\
\hline
\end{tabular}

Q21. ¿Se han producido cambios en su estructura de costes?

\begin{tabular}{|l|c|}
\hline Opciones de respuesta & Respuestas \\
\hline Sí & $66,17 \%$ \\
\hline No & $33,83 \%$ \\
\hline
\end{tabular}

Q22. ¿Se ha reducido el coste de servir a un cliente?

\begin{tabular}{|l|c|}
\hline Opciones de respuesta & Respuestas \\
\hline Sí & $49,24 \%$ \\
\hline No & $50,76 \%$ \\
\hline
\end{tabular}

Q23. Indique si han cambiado las fuentes de ingresos

\begin{tabular}{|c|c|}
\hline Opciones de respuesta & Respuestas \\
\hline Sí & $27,27 \%$ \\
\hline No & $72,73 \%$ \\
\hline
\end{tabular}

Q24. En caso de haber iniciado durante los últimos años alguna estrategia de transformación digital, valore el éxito

\begin{tabular}{|c|c|c|c|}
\hline $\begin{array}{c}\text { Se ha } \\
\text { fracasado }\end{array}$ & $\begin{array}{c}\text { Por debajo } \\
\text { de las } \\
\text { expectativas }\end{array}$ & $\begin{array}{c}\text { Se han } \\
\text { cumplido las } \\
\text { expectativas }\end{array}$ & $\begin{array}{c}\text { Mejora de las } \\
\text { expectativas } \\
\text { iniciales }\end{array}$ \\
\hline $0,85 \%$ & $39,83 \%$ & $46,61 \%$ & $12,71 \%$ \\
\hline
\end{tabular}


Q25. ¿Cuánto tiempo han tardado en su compañía en tener resultados tangibles como consecuencia de la implementación y ejecución de un programa de transformación digital?

\begin{tabular}{|c|c|c|c|c|}
\hline $\begin{array}{c}\text { Menos de } \\
\mathbf{1} \text { año }\end{array}$ & $\begin{array}{c}\text { Entre 1 y } \\
\mathbf{2} \text { años }\end{array}$ & $\begin{array}{c}\text { Entre 2 y } \\
\mathbf{3} \text { años }\end{array}$ & $\begin{array}{c}\text { Más de } \\
\mathbf{3} \text { años }\end{array}$ & $\begin{array}{c}\text { No ha sido } \\
\text { posible obtener } \\
\text { resultados } \\
\text { tangibles }\end{array}$ \\
\hline $\mathbf{1 6 , 1 3 \%}$ & $33,87 \%$ & $29,03 \%$ & $8,06 \%$ & $12,90 \%$ \\
\hline
\end{tabular}

Q26. ¿Qué unidad impulsa y lidera el proceso de transformación digital en su empresa?

\begin{tabular}{|l|c|}
\hline Opciones de respuesta & Respuestas \\
\hline Dirección General & $82,68 \%$ \\
\hline Área funcional (aparte del área de tecnología) & $14,96 \%$ \\
\hline Dirección de Sistemas o Tecnología & $22,05 \%$ \\
\hline Unidad de negocio & $10,24 \%$ \\
\hline Una entidad jurídica independiente & $1,57 \%$ \\
\hline Organización híbrida & $3,94 \%$ \\
\hline Otra. Indicar: & $11,02 \%$ \\
\hline
\end{tabular}

Q27. ¿Quién es el responsable último de la transformación digital en su empresa?

\begin{tabular}{|l|r|}
\hline Opciones de respuesta & Respuestas \\
\hline CEO & $76,38 \%$ \\
\hline CIO & $9,45 \%$ \\
\hline CDO & $3,15 \%$ \\
\hline COO & $3,15 \%$ \\
\hline CMO & $0,79 \%$ \\
\hline CFO & $1,57 \%$ \\
\hline
\end{tabular}

Q28. ¿En su empresa coexisten...?

\begin{tabular}{|l|c|c|}
\hline & Sí & No \\
\hline $\begin{array}{l}\text {...pruebas de concepto, pilotos, con su } \\
\text { modelo de negocio tradicional }\end{array}$ & $75,20 \%$ & $24,80 \%$ \\
\hline $\begin{array}{l}\text {...el modelo de negocio tradicional con } \\
\text { un modelo de negocio emergente }\end{array}$ & $61,54 \%$ & $38,46 \%$ \\
\hline
\end{tabular}


Q29. ¿Qué tipo de metodologías de desarrollo/construcción se utilizan en su empresa?

Opciones de respuesta

Respuestas

Waterfall/gestión de proyectos tradicional. Una única entrega

de valor con una definición inicial lo suficientemente completa incluyendo propósito, funcionalidad, diseño y construcción.

Modelos ágiles: entrega temprana y continua de valor, por ello su principal característica es realizar entregas rápidas y continuas. EI producto se divide en distintas partes con valor para que cada una de ellas se complete y entregue en pocas semanas.

Lean startup: construcción iterativa fundamentada en la generación de un producto mínimo viable que evalúa las hipótesis fundamentales de un negocio y permite la toma de decisiones temprana.

Q30. ¿Ha sido necesario incorporar nuevas capacidades en la empresa?

\begin{tabular}{|c|c|}
\hline Opciones de respuesta & Respuestas \\
\hline Sí & $91,27 \%$ \\
\hline No & $8,73 \%$ \\
\hline
\end{tabular}

\section{Q31. En caso afirmativo:}

\begin{tabular}{|l|c|}
\hline Opciones de respuesta & Respuestas \\
\hline Formación interna & $62,61 \%$ \\
\hline Alianzas estratégicas & $40,87 \%$ \\
\hline Nueva contratación & $70,43 \%$ \\
\hline
\end{tabular}

Q32. ¿Hay distintos KPI entre el modelo de negocio emergente y el tradicional?

\begin{tabular}{|l|c|}
\hline Opciones de respuesta & Respuestas \\
\hline Sí & $57,85 \%$ \\
\hline No & $42,15 \%$ \\
\hline
\end{tabular}


Q33. Como consecuencia de la transformación digital, dhay cambios importantes en los indicadores de gestión y en el modelo de incentivos/compensación?

\begin{tabular}{|l|c|}
\hline \multicolumn{1}{|l|}{ Opciones de respuesta } & Respuestas \\
\hline $\begin{array}{l}\text { No, ni en los indicadores de gestión ni en el modelo } \\
\text { de incentivos/compensación }\end{array}$ & $32,79 \%$ \\
\hline Solo en los indicadores de gestión & $29,51 \%$ \\
\hline Solo en el modelo de incentivos/compensación & $2,46 \%$ \\
\hline $\begin{array}{l}\text { Tanto en los indicadores de gestión como en el } \\
\text { modelo de incentivos/compensación }\end{array}$ & $35,25 \%$ \\
\hline
\end{tabular}

\section{Q34. Indique si se han utilizado algunos de los siguientes modelos, metodologías o procesos para la transformación del modelo de negocio de la empresa}

\begin{tabular}{|c|c|}
\hline Opciones de respuesta & Respuestas \\
\hline $\begin{array}{l}\text { Open innovation: implica la participación y/o coordinación de terceros } \\
\text { actores (externos a la compañía) en el proceso de innovación Inversión } \\
\text { (clientes, proveedores, startups, etc.). }\end{array}$ & $47,71 \%$ \\
\hline $\begin{array}{l}\text { Cocreación de valor: busca la creación de valor mediante un acercamiento } \\
\text { y una apertura del diálogo tanto con los clientes como con los empleados y } \\
\text { proveedores para hacerlos partícipes en la definición de sus interacciones } \\
\text { con la empresa. }\end{array}$ & $51,38 \%$ \\
\hline $\begin{array}{l}\text { Deep-dive o inmersión profunda: consiste en sumergir rápidamente a un } \\
\text { grupo o equipo de personas en una situación de resolución de problemas o } \\
\text { creación de ideas (brainstorming). }\end{array}$ & $23,85 \%$ \\
\hline $\begin{array}{l}\text { Design thinking: persigue, mediante una definición inicial del problema, } \\
\text { la implementación de soluciones, pero siempre con las necesidades de } \\
\text { los usuarios/clientes en el núcleo conceptual de desarrollo. Integra cinco } \\
\text { pasos: empatizar, definir, idear, prototipar y probar. }\end{array}$ & $50,46 \%$ \\
\hline $\begin{array}{l}\text { Jobs to Be Done (JTBD): pretende comprender los factores que hacen } \\
\text { evolucionar rápidamente los intereses de los clientes. Pone el foco en las } \\
\text { dimensiones funcionales, sociales y emocionales que explican su toma de } \\
\text { decisiones. }\end{array}$ & $18,35 \%$ \\
\hline $\begin{array}{l}\text { Customer journey mapping: permite detectar, a través del trazado de un } \\
\text { mapa de las etapas que recorre una persona desde que le sobreviene una } \\
\text { necesidad hasta que compra, cuál de aquellas es la que genera mayor valor } \\
\text { para la experiencia del cliente en su proceso de vinculación con la compañía }\end{array}$ & $46,79 \%$ \\
\hline $\begin{array}{l}\text { A/B testing: consiste en desarrollar y lanzar dos versiones de un mismo } \\
\text { elemento (producto/servicio) y medir cuál funciona mejor. }\end{array}$ & $18,35 \%$ \\
\hline $\begin{array}{l}\text { Planificación estratégica: se trata de un proceso sistemático de desarrollo e } \\
\text { implementación de planes para alcanzar propósitos u objetivos concretos } \\
\text { para empresa. }\end{array}$ & $60,55 \%$ \\
\hline $\begin{array}{l}\text { Hackathons: permite la organización de eventos y experiencias colectivas } \\
\text { para lograr a través de tecnología un objetivo en común (la resolución de } \\
\text { problemas concretos de negocio). Normalmente está ligado a entornos de } \\
\text { desarrollo y programación, pero no exclusivamente. }\end{array}$ & $10,09 \%$ \\
\hline $\begin{array}{l}\text { Rapid prototyping: es el desarrollo y presentación a los usuarios de } \\
\text { prototipos en iteraciones relativamente rápidas para lograr una versión de } \\
\text { producto mínimo viable lo antes posible. }\end{array}$ & $18,35 \%$ \\
\hline Otros (especificar): & $2,75 \%$ \\
\hline
\end{tabular}


Q35. Considera usted que...

\begin{tabular}{|l|c|c|}
\hline & Sí & No \\
\hline $\begin{array}{l}\text {...ha cambiado la estructura } \\
\text { organizativa de su organización }\end{array}$ & $52,76 \%$ & $47,24 \%$ \\
\hline $\begin{array}{l}\text {...ha habido un cambio cultural en su } \\
\text { organización }\end{array}$ & $66,40 \%$ & $33,60 \%$ \\
\hline
\end{tabular}




\section{Sobre Penteo}

Penteo es el analista de tecnologías de la información ( $\mathrm{TI}$ ) independiente que lidera la mayor comunidad de conocimiento de TI de España y ofrece un servicio especialmente diseñado para directivos con influencia o responsabilidad en las decisiones TI-negocio, ayudándoles a garantizar el acierto en estas, compartiendo conocimiento, asesorándoles y facilitándoles el networking. Para proveedores de TI, Penteo aporta información del mercado sobre tendencias y posicionamientos, y proporciona apoyo experto con el que maximizar el éxito en las estrategias.

Desde hace más de 25 años, da servicio a más de 200 compañías e instituciones de primer nivel del mercado español, ayudando a minimizar riesgo, tiempo y coste, y extraer de las TI y las tecnologías digitales el máximo valor para el negocio.
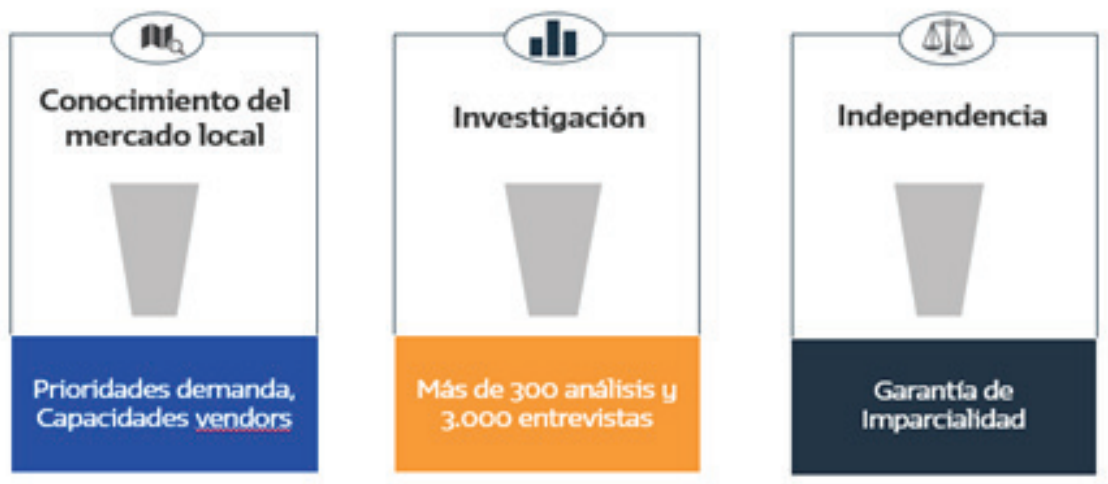

Tu asesor TI de confianza que proporciona conocimiento y apoyo experto e independiente.

Toni Guerra Cortada, Head of Product \& Madrid Office. Experiencia internacional contrastada en desarrollo de negocio, estrategia digital y análisis de mercado en diversas compañías multinacionales. Actualmente lidera el área de producto y la oficina de Madrid de PENTEO, donde ayuda a directivos al diseño y ejecución de la estrategia digital más adecuada para sus organizaciones.

José Luis Pérez Tejada, Head of Operations. Con más de 10 años de experiencia en implantación tecnológica asesoramiento IT a clientes. Actualmente lidera el área de análisis y delivery de PENTEO, ayudando a los directivos en la definición de programas de estrategia digital. 


\section{Sobre el IESE}

IESE Business School es la escuela de posgrado en dirección de empresas de la Universidad de Navarra. Fundada en 1958 como Instituto de Estudios Superiores de la Empresa (IESE) en Barcelona, donde tiene su campus principal, en 1963 formó una alianza con la Harvard Business School (HBS) y lanzó el primer programa MBA de dos años impartido en Europa. Actualmente, el IESE es una de las escuelas de negocios más importantes del mundo y dispone de otros cuatro campus en Madrid, Múnich, Nueva York y São Paulo. Se sitúa entre las diez mejores del mundo en los rankings de programas de formación para directivos (executive education), Master of Business Administration (MBA) y Executive MBA.

Este estudio ha sido impulsado por el IESE Digital Ecosystem, encuentro sectorial del ecosistema digital bajo la dirección académica de los profesores Joan Enric Ricart y Javier Zamora.

Javier Zamora es profesor ordinario de la Práctica de la Dirección y director del Departamento de Sistemas de Información del IESE Business School. Cuenta con un doctorado en Ingeniería Eléctrica por la Columbia University y es ingeniero superior de Telecomunicación por la Universitat Politècnica de Catalunya, además de tener un PDG por el IESE. Es director académico de la Digital Ecosystem Industry Meeting del IESE, así como del Programa Enfocado Transformación Digital para la Alta Dirección. Sus áreas de interés se centran en las organizaciones impulsadas por los datos y la inteligencia artificial y su impacto en la transformación digital.

Joan Enric Ricart, fellow de la Strategic Management Society (SMS) y de European Academy of Management (EURAM) es profesor del Dirección Estratégica y dirige la Cátedra Carl Schroeder en el IESE Business School. En 1993 fue nombrado director del Departamento de Dirección Estratégica hasta julio del 2016. Asimismo, fue director del programa doctoral (1995-2006) y decano asociado de Investigación (2001-2006). Fue el presidente fundador de la EURAM, presidente de la SMS y vicepresidente de la Iberoamerican Academy of Management; director del Centro de Globalización y Estrategia del IESE, codirector académico del IESE Cities in Motion y director Académico del Specialist Centre on PPPs in Smart and Sustainable Cities (PPP for Cities). También es miembro del Advisory Board de la Urban Development and Services Initiative del World Economic Forum. Sus áreas de interés están focalizadas en el impacto de la sostenibilidad y la transformación digital en la innovación en modelos de negocio, la trasformación de las ciudades, y los nuevos modelos de gobernanza. 


\section{www.iese.edu}

Barcelona

Madrid

Munich

New York

São Paulo 